

\section{DISCLAIMER}

This report was prepared as an account of work sponsored by an agency of the United States Government. Neither the United States Government nor any agency Thereof, nor any of their employees, makes any warranty, express or implied, or assumes any legal liability or responsibility for the accuracy, completeness, or usefulness of any information, apparatus, product, or process disclosed, or represents that its use would not infringe privately owned rights. Reference herein to any specific commercial product, process, or service by trade name, trademark, manufacturer, or otherwise does not necessarily constitute or imply its endorsement, recommendation, or favoring by the United States Government or any agency thereof. The views and opinions of authors expressed herein do not necessarily state or reflect those of the United States Government or any agency thereof. 


\section{DISCLAIMER}

Portions of this document may be illegible in electronic image products. Images are produced from the best available original document. 


\section{Printed in the United States of America. Available from}

National Technical Information Service

U.S. Department of Commerce 5285 Port Royal Road, Springfield, Virginia 22161

Price: Printed Copy $\$ 5.25$; Microfiche $\$ 3.00$

This report was prepared as an account of work sponsored by an agency of the United States Government. Neither the United States Government nor any agency thereof, nor any of their employees, contractors, subcontractors, or their employees, makes any warranty, express or implied, nor assumes any legal liability or responsibility for any third party's use or the results of such use of any information, apparatus, product or process disclosed in this report, nor represents that its use by such third party would not.infringe privately owned rights. 
ORNL / TM-5578

Contract No. W-7405-eng-26

\title{
A TWO-DIMENSIONAL TRANSIENT FAR-FIELD ANALYSIS FOR THE EXCESS TEMPERATURE FROM AN ARBITRARY SOURCE
}

\author{
Alan J. Witten \\ Energy Division \\ Ed C. L.ong \\ Computer Sciences Division
}

Date Published - July 1978

$$
\begin{aligned}
& \text { This report was prepared as an account of work } \\
& \text { sponsored by the United States Covernmentl. Netcher the } \\
& \text { United States nor the United States Department of } \\
& \text { Energy, nor any of their employees, nor any of their } \\
& \text { contractors, subcontractors, or their employees, makes } \\
& \text { any wartanty, express or imptied, or assumes any legal } \\
& \text { liability or responsibility for the accuracy, completeness } \\
& \text { or usefulness of any information, apparatus, product or } \\
& \text { proces disclosed, or represents that its use would not } \\
& \text { infringe privately owned nights. }
\end{aligned}
$$

NOTICE This document contains information of a preliminary nature. It is subject to revision or corroction and therefore does not represent a final report.

\author{
OAK RIDGE NATIONAL LABORATORY \\ Oak Ridge, Tennessee 37830 \\ operated by \\ UNION CARBIDE CORPORATION \\ for the \\ DEPARTMENT OF ENERGY
}




\section{THIS PAGE}

\section{WAS INTENTIONALLY LEFT BLANK}


A TWO-DIMENSIONAL TRANSIENT FAR-FIELD ANALYSIS FOR THE

EXCESS TEMPERATURE FROM AN ARBITRARY SOURCE

$$
\text { Alan J. Witten* Ed C. Longt }
$$

\section{ABSTRACT}

An analytic solution is presented for the two-dimensional timedependent advective diffusion equation governing the distribution of excess temperature in a river of uniform width, depth, and downstream flow. The solution is also applicable to a straight coastline with uniform longshore flow. Exact solutions are obtained for a point heat source and a particular line heat source, while an approximate representation is given for an arbitrary time-varying heat source. These solutions are incorporated into a computer program which calculates excess temperature and time rate-of-change of excess temperature in a river or coast as a result of waste heat discharged from various transient sources.

\footnotetext{
* ORNL Energy Division.

${ }^{\dagger}$ ORNL Computer Sciences Division.
} 
The most efficient system for dissipating excess heat from a nuclear reactor, as well as from other thermal sources, is once-through cooling. However, this system can frequently be the least desirable, because of its adverse environmental impacts, notably that the excess temperature produced in the receiving body of water can destroy or inhibit the growth of aquatic organisms. In rivers, it is particularly important to avoid full channel blockage so that aquatic life can have passage without exposure to significant temperature differences. Therefore, a predictive model in at least two dimensions is required to determine if a given discharge will satisfy an imposed restriction on the spatial distribution of excess temperature. Because aquatic life is susceptible to cold shock, it is also desirable to have the capability to predict the transient thermal behavior of a plume from a time-varying source. In the past, the problems of cold shock and excess temperature have been considered separately in analytic models. A number of simple twodimensional steady-state thermal models are reviewed in a state-of-theart report by Policastro and Tokar (1972). In addition, a number of more sophisticated analytic solutions have been given by Sayre and Chang (1968), Cleary and Adrian (1973), and Yeh and Tsai (1976). Yeh and Tsai address a quite general problem considering both transient flow and three-dimensional sources; however, for this problem numerical integration is required. The work of Cleary and Adrian is restricted to a pointsource instantaneous discharge. Little analytical work has been done on the cold shock problem. There are one-dimensional transient models such as that by Pilati (1973), which solves the initial-value problem for sudden plant shutdown.

The two-dimensional transient model presented here is for the farfield and is valid only in the region where the excess momentum from the discharge is insignificant. Consideration is restricted in this paper to straight coastlines and rivers of uniform depth and width with a steady uniform downstream or longshore flow. The restriction to uniform width is a result of the time-dependence of the model. Coordinate 
transforms such as that used by Dresner (1973) are invariant only for the steady-state form of the equation and, therefore, cannot be used here.

Subject to these assumptions, the program developed here enables exact solutions to be obtained for a point source and for a Gaussian line source normal to the shore. This paper also discusses an approximate technique for dealing with other types of source distributions.

\section{ANALYSIS FOR A RIVER}

The present analysis establishes a coordinate system for the hypothetical river under study, with the $x$-axis pointing downstream, the $y-$ axis pointing cross-stream, and the origin on one shore, as shown in Fig. 1. The width of the river is $b$, and the uniform downstream velocity is $u_{0}$. The equation governing the excess temperature $\Delta \mathrm{T}(x, y, t)$ is

$$
\frac{\partial(\Delta T)}{\partial t}+u_{0} \frac{\partial(\Delta T)}{\partial x}-\alpha \frac{\partial^{2}(\Delta T)}{\partial y^{2}}=q(t) f(x, y)-\frac{K}{\rho c_{p} d} \Delta T,
$$

where $\alpha$ is the eddy diffusivity, $q(t) f(x, y)$ is the two-dimensional transient source strength, $K$ is the surface heat exchange coefficient, $\rho$ is the density, $c_{p}$ is the specific heat, and $d$ is the depth. Downstream diffusion is omitted in Eq. (1). This is acceptable in most cases because the dominant downstream transport mechanism is advection. Analytic solutions can still be obtained if the term for downstream diffusion is retained (see Cleary and Adrian (1973) and Yeh and Tsai (1976)]; however, numerical integration is required to consider transient sources. The appropriate boundary conditions are insulated river banks and zero excess temperature far upstream. These conditions can be written as

$$
\left.\frac{\partial(\Delta T)}{\partial y}\right|_{y=0, b}=\left.\Delta T\right|_{x=-\infty}=0
$$


ORNL-DWG 78-4851
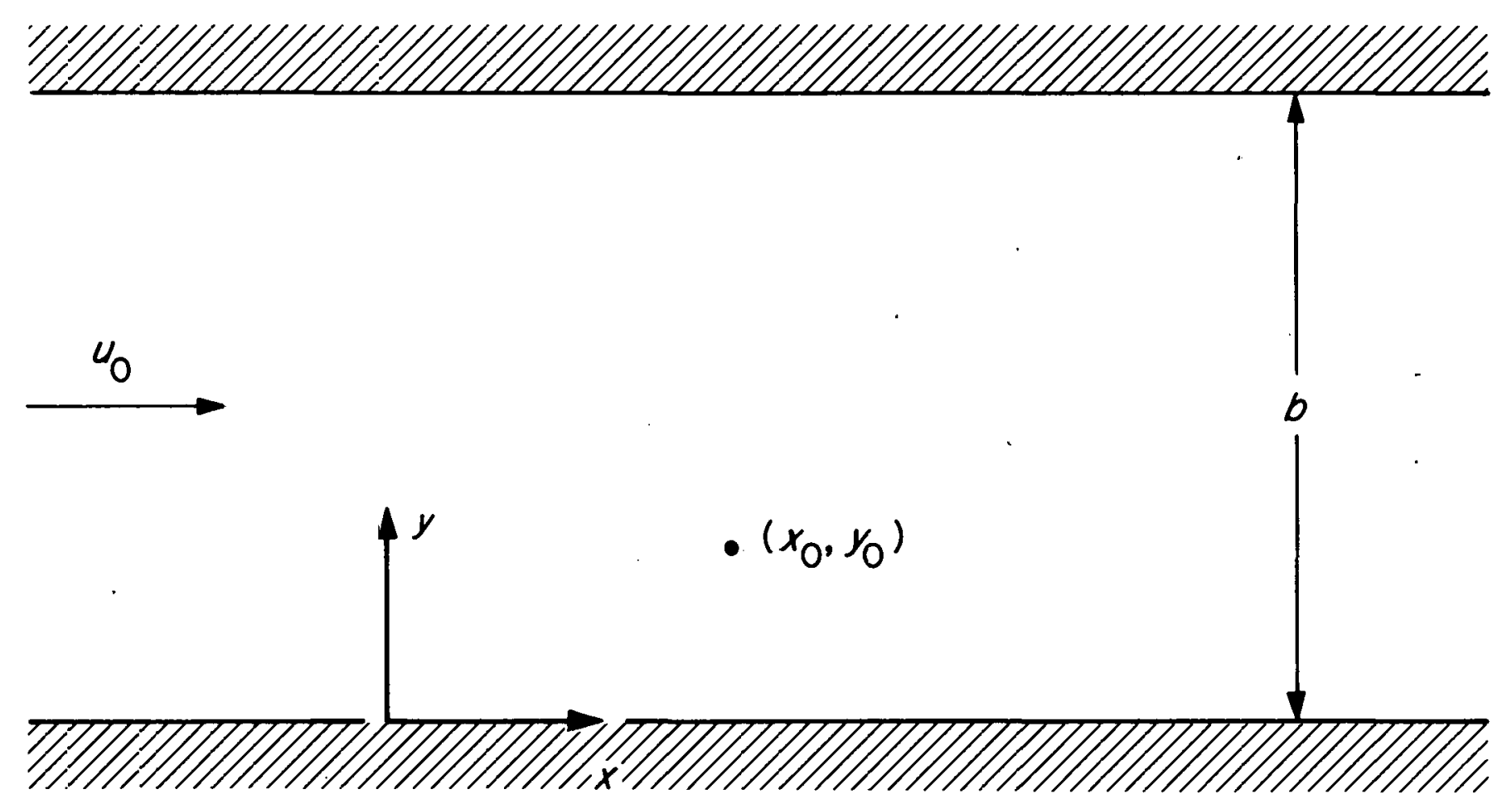

Fig. 1. Basic coordinate system. 
For mathematical convenience, the source strength $q(t)$ and the excess temperature $\Delta T$ are set equal to zero initially $(t=0)$. It is also assumed that $q(t)$ is, or can be approximated as, a piecewise continuous function, and $|q(t)|$ does not increase too rapidly as $t$ goes to infinity. With these assumptions, Eq. (1) can be Laplace transformed to give

$$
s \hat{T}+u_{0} \frac{\partial \hat{T}}{\partial x}-\alpha \frac{\partial^{2} \hat{T}}{\partial y^{2}}=\hat{q}(s) f(x, y)-\hat{k T},
$$

where

$$
\hat{T}(x, y, s)=\mathscr{L}[\Delta T(x, y, t)]=\int_{0}^{\infty} \Delta T(x, y, t) e^{-s t} d t
$$

and $k=K / \rho c_{p} d$. Equation (3) can be simplified by multiplying by $\exp \left[(s+k) x / u_{0}\right]$ and defining

$$
\hat{\chi}(x, y, s)=\exp \left[(s+k) x / u_{0}\right] \hat{\mathrm{T}}(x, y, s) .
$$

This results in the differential equation

$$
\frac{\partial^{2} \hat{x}}{\partial y^{2}}-\frac{u_{0}}{\alpha} \frac{\partial \hat{x}}{\partial x}=-\frac{\hat{q}(s)}{\alpha} f(x, y) \exp \left[(s+k) x / u_{0}\right],
$$

subject to

$$
\left.\frac{\partial \hat{x}}{\partial y}\right|_{y=0, b}=\left.\hat{x}\right|_{x=-\infty}=0
$$

Formally, the solution to Eq. (6), with the boundary conditions prescribed by Eq. (7), can be written

$$
\hat{\chi}(x, y, s)=\int_{-\infty}^{x} d x^{\prime} \int_{0}^{b} d y^{\prime} F\left(x^{\prime}, y^{\prime}, s\right) G\left(x, y, x^{\prime}, y^{\prime}\right),
$$


where

$$
F(x, y, s)=\frac{\hat{q}(s)}{4 \pi \alpha} f(x, y) \exp \left[(s+k) x / u_{0}\right]
$$

The Green's function $G\left(x, y, x^{\prime}, y^{\prime}\right)$ satisfies

$$
\frac{\partial^{2} G}{\partial y^{2}}-\frac{u_{0}}{\alpha} \frac{\partial G}{\partial x}=-4 \pi \delta\left(x-x^{\prime}\right) \delta\left(y-y^{\prime}\right)
$$

where $\delta(x)$ is the Dirac delta function and subject to the boundary conditions

$$
\left.\frac{\partial G}{\partial y}\right|_{y=0, b}=\left.G\right|_{x=-\infty}=0
$$

The free-space Green's function [Morse and Feshbach (1953)] is

$$
G_{\infty}\left(x, y, x^{\prime}, y^{\prime}\right)=\frac{2 \sqrt{\pi}}{a \sqrt{x-x^{\prime}}} U\left(x-x^{\prime}\right) \exp \left[-a^{2}\left(y-y^{\prime}\right)^{2} / 4\left(x-x^{\prime}\right)\right],
$$

where $a=\sqrt{u_{0} / \alpha}$ and $U(x)$ is the unit step function. To satisfy the boundary conditions at $y=0$ and $y=b$, the point source at $\left(x^{\prime}, y^{\prime}\right)$ must be imaged in these boundaries. This results in sources located at $\left(x^{\prime}, y^{\prime} \pm 2 n b\right)$ and $\left(x^{\prime},-y^{\prime} \pm 2 n b\right)$ for $n=0,1,2, \ldots$. The desired Green's function is obtained by summing over these sources to give

$$
\begin{aligned}
G\left(x, y, x^{\prime}, y^{\prime}\right)= & \frac{2 \sqrt{\pi}}{a \sqrt{x-x^{\prime}}} U\left(x-x^{\prime}\right) \\
& \cdot \sum_{n=-\infty}^{\infty}\left\{\exp \left[-\frac{a^{2}\left(y-y^{\prime}-2 n b\right)^{2}}{4\left(x-x^{\prime}\right)}\right]\right. \\
& \left.+\exp \left[-\frac{a\left(y+y^{\prime}-2 n b\right)^{2}}{4\left(x-x^{\prime}\right)}\right]\right\} .
\end{aligned}
$$


Substituting Eqs. (9) and (13) into Eq. (8) gives

$$
\begin{aligned}
\hat{x}(x, y, s)= & \hat{q}(s) \\
2 \alpha a \sqrt{\pi} & \int_{-\infty}^{x} d x^{\prime} \int_{0}^{b} d y^{\prime} \frac{f\left(x^{\prime}, y^{\prime}\right)}{\sqrt{x-x^{\prime}}} \exp \left[(s+k) x^{\prime} / u_{0}\right] U\left(x-x^{\prime}\right) \\
& \cdot \sum_{n=-\infty}^{\infty}\left\{\exp \left[-\frac{a^{2}\left(y-y^{\prime}-2 n b\right)^{2}}{4\left(x-x^{\prime}\right)}\right]\right. \\
& \left.+\exp \left[-\frac{a^{2}\left(y+y^{\prime}-2 n b\right)^{2}}{4\left(x-x^{\prime}\right)}\right]\right\} .
\end{aligned}
$$

If the spatial distribution of the source $f(x, y)$ has a simple form, Eq. (14) can be easily integrated. A few such cases will be considered here.

\section{Point Source}

For a point source located at $\left(x_{0}, y_{0}\right)$, the function $f(x, y)$ becomes

$$
f(x, y)=\delta\left(x-x_{0}\right) \delta\left(y-y_{0}\right)
$$

The integration of Eq. (14) now reduces to the evaluation of the integrand at $x^{\prime}=x_{0}$ and $y^{\prime}=y_{0}$ to give

$$
\begin{gathered}
\left.\hat{x}(x, y, s)=\frac{\hat{q}(s)}{2 a \alpha \sqrt{\pi\left(x-x_{0}\right)}} \exp \mid(s+k) x_{0} / u_{0}\right] U\left(x-x_{0}\right) \\
\cdot \sum_{n=-\infty}^{\infty}\left\{\exp \left[-\frac{a^{2}\left(y-y_{0}-2 n b\right)^{2}}{4\left(x-x_{0}\right)}\right]\right. \\
\left.\quad+\exp \left[-\frac{a^{2}\left(y+y_{0}-2 n b\right)^{2}}{4\left(x-x_{0}\right)}\right]\right\} .
\end{gathered}
$$

To obtain $\hat{T}(x, y, s)$, Eq. (16) is multiplied by $\exp \left[-(s+k) x / u_{\eta}\right]$. The time dependence can be recovered by performing the inverse transformation 


$$
\begin{aligned}
& \mathscr{L}^{-1}\left\{\exp \left[-\frac{s+k}{u_{0}}\left(x-x_{0}\right)\right] \hat{q}(s)\right\} \\
& \quad=\frac{1}{2 \pi i} \exp \left[-\frac{k}{u_{0}}\left(x-x_{0}\right)\right] \int_{c-i \infty}^{c+i \infty} \hat{q}(s) \exp \left[-\frac{s}{u_{0}}\left(x-x_{0}\right)\right] \exp (s t) d s .
\end{aligned}
$$

By translation, this inverse transform is simply

$$
\exp \left[-\frac{k}{u_{0}}\left(x-x_{0}\right)\right] q\left(t-\frac{x-x_{0}}{u_{0}}\right) U\left(t-\frac{x-x_{0}}{u_{0}}\right) .
$$

Finally, the functional form for the excess temperature is

$$
\begin{aligned}
\Delta T(x, y, t)= & \frac{q\left(t-\frac{x-x_{0}}{u_{0}}\right)}{2 \sqrt{\pi u_{0} \alpha\left(x-x_{0}\right)}} \exp \left[-\frac{k}{u_{0}}\left(x-x_{0}\right)\right] U\left(t-\frac{\left.x-x_{0}\right)}{u_{0}}\right) U\left(x-x_{0}\right) \\
& \cdot \sum_{n=-\infty}^{\infty}\left\{\exp \left[-\frac{u_{0}\left(y-y_{0}-2 n b\right)^{2}}{4 \alpha\left(x-x_{0}\right)}\right]\right. \\
& \left.+\exp \left[-\frac{u_{0}\left(y+y_{0}-2 n b\right)^{2}}{4 a\left(x-x_{0}\right)}\right]\right\}
\end{aligned}
$$

Some insight can be gained by inspection of this equation. First, there is an excess temperature front being advected downstream. This feature is apparent in the step function $U\left(t-\frac{x-x_{0}}{u_{0}}\right)$. At time $t$, the excess temperature only extends to $x=x_{0}+u_{0} t$, and there is no excess temperature beyond this point. Another feature is the linear dependence of the excess temperature on the magnitude of the source strength. In other words, if $\Delta T$ is known for a source strength $q$, then the excess temperature from a source of strength $\gamma q$ is merely $\gamma \Delta T$.

\section{Gaussian Line Source Normal to Shore}

Most near-field models are Gaussian. Therefore, it is desirable to integrate Equation (14) for a source strength having such a distribution. This integration should produce, in most situations, a more realistic 
plume than a point source. For simplicity, consider a Gaussian line source normal to the shore with the mean at a point $\left(x_{0}, y_{0}\right)$.. In this case, the function $f(x, y)$ has the form

$$
f(x, y)=\delta\left(x-x_{0}\right) A \exp \left[-\frac{\left(y-y_{0}\right)^{2}}{\sigma^{2}}\right],
$$

where $\sigma$ is defined as the standard deviation and $A$ is a normalization constant. Now, Equation (14) becomes

$$
\begin{aligned}
\hat{x}(x, y, s)= & \frac{\hat{q}(s)}{2 a \alpha \sqrt{\pi\left(x-x_{0}\right)}} A \exp \left[\left(\frac{s+k}{u_{0}}\right) x_{0}\right] U\left(x-x_{0}\right) \int_{0}^{b} d y^{\prime} \exp \left[-\frac{\left(y^{\prime}-y_{0}\right)^{2}}{\sigma^{2}}\right] \\
& \cdot \sum_{n=-\infty}^{\infty}\left\{\exp \left[-\frac{a^{2}\left(y-y^{\prime}-2 n b\right)^{2}}{4\left(x-x_{0}\right)}\right]\right. \\
& \left.\quad+\exp \left[-\frac{a^{2}\left(y+y^{\prime}-2 n b\right)^{2}}{4\left(x-x_{0}\right)}\right]\right\}
\end{aligned}
$$

To perform this integration, consider the integral

$$
I=\int_{0}^{h} d y^{\prime} \exp \left[-\frac{\left(y^{\prime}-y_{0}\right)^{2}}{\sigma^{2}}\right] \exp \left[-\frac{a^{2}\left(y \pm y^{\prime}-2 n b\right)^{2}}{4\left(x-x_{0}\right)}\right]
$$

This can be written in the form

$$
I=\int_{0}^{b} d y^{\prime} \exp \left[-\left(c_{1} y^{\prime 2}+2 c_{2} y^{\prime}+c_{3}\right)\right]
$$

where

$$
c_{1}=\frac{1+\beta^{2}}{\sigma^{2}}, c_{2}=-\frac{\left[y_{0} \pm \beta^{2}(y-2 n b)\right]}{\sigma^{2}}, c_{3}=\frac{y_{0}^{2}+\beta^{2}(y-2 n b)^{2}}{\sigma^{2}},
$$

and $\beta^{2}=\frac{a^{2} \sigma^{2}}{4\left(x-x_{0}\right)}$. In this form, Eq. (22) can be integrated to give 


$$
I=\frac{1}{2} \sqrt{\frac{\pi}{c_{1}}} \exp \left[\frac{c_{2}{ }^{2}-c_{1} c_{3}}{c_{1}}\right]\left\{\operatorname{erf}\left(\sqrt{c_{1}} b+\frac{c_{2}}{\sqrt{c_{1}}}\right)-\left(\operatorname{erf} \frac{c_{2}}{\sqrt{c_{1}}}\right)\right\}
$$

or

$$
\begin{gathered}
I=\frac{\sigma}{2} \sqrt{\frac{\pi}{1+\beta^{2}}} \exp \left[-\frac{\beta^{2}}{\sigma^{2}\left(1+\beta^{2}\right)}\left(y \pm y_{0}-2 n b\right)^{2}\right] \\
\cdot\left\{\operatorname{erf}\left[\sqrt{1+\beta^{2}} \frac{b}{\sigma} \mp \frac{\left(\beta^{2} y \pm y_{0}-2 n \beta^{2} b\right)}{\sigma \sqrt{1+\beta^{2}}}\right]\right. \\
\left. \pm \operatorname{erf}\left[\frac{\beta^{2} y \pm y_{0}-2 n \beta^{2} b}{\sigma \sqrt{1+\beta^{2}}}\right]\right\} .
\end{gathered}
$$

Substituting Eq. (24) into Eq. (20), multiplying this result by $\exp \left[-\frac{(s+k)}{u_{0}} x\right]$ and taking the inverse of the Laplace transform in the manner shown by Eq. (17) results in

$$
\begin{aligned}
& \Delta T(x, y, t)=-\frac{\sigma q\left[t-\left(x-x_{0}\right) / u_{0}\right]}{2 \sqrt{u_{0}} \sqrt{4 \alpha\left(x-x_{0}\right)+u_{0} \sigma^{2}}} A \exp \left[-\frac{k}{u_{0}}\left(x-x_{0}\right)\right] U\left(t-\frac{x-x_{0}}{u_{0}}\right) \\
& U\left(x-x_{0}\right) \sum_{n=-\infty}^{\infty}\left\{\exp \left[-\frac{u_{0}\left(y_{1}+y_{0}-2 n b\right)^{2}}{4 \alpha\left(x-x_{0}\right)+u_{0} \sigma^{2}}\right]\right. \\
& \text { - }\left[\operatorname{erf}\left(\sqrt{1+\beta^{2}} \frac{b}{\sigma}-\frac{\beta^{2} y+y_{0}-2 n \beta^{2} b}{\sigma \sqrt{1+\beta^{2}}}\right)\right. \\
& \left.+\operatorname{erf} \frac{\beta^{2} y+y_{0}-2 n \beta^{2} b}{\sigma \sqrt{1+\beta^{2}}}\right] \\
& +\exp \left[-\frac{u_{0}\left(y-y_{0}-2 n b\right)^{2}}{4 \alpha\left(x-x_{0}\right)+u_{0} \sigma^{2}}\right] \\
& \text { - }\left[\operatorname{erf}\left(\sqrt{1+\beta^{2}} \frac{b}{\sigma}+\frac{\beta^{2} y-y_{0}-2 n \beta^{2} b}{\sigma \sqrt{1+\beta^{2}}}\right)\right. \\
& \left.\left.-\operatorname{erf} \frac{\beta^{2} y-y_{0}-2 n \beta^{2} b}{\sigma \sqrt{1+\beta^{2}}}\right]\right\} \text {. }
\end{aligned}
$$


The difficult form of Equation (25) is deceiving. It is computationally straightforward and, in most instances, converges rapidly for downstream distances that are not too excessive.

\section{Arbitrary Source Distribution}

An arbitrary source distribution, or multiple sources, can be approximated by a number of point sources. To do this, assume that the spatial source function has the form

$$
f(x, y)=\sum_{m=1}^{M} f_{m} \delta\left(x-x_{m}\right) \delta\left(y-y_{m}\right)
$$

This is the sum of $M$ point sources of various strengths $f_{m}$ located at points $\left(x_{m}, y_{m}\right)$, where $m=1,2, \ldots, M$. From substituting Eq. (26) in Eq. (6), it is evident that the excess temperature resulting from multiple point sources is simply the sum of the excess temperatures resulting from the individual point sources. Therefore, the excess temperature can be represented by a superposition of the point source solutions given by Eq. (18) and can be written as

$$
\begin{aligned}
\Delta T(x, y, t)= & \sum_{m=1}^{M}\left(\frac{q\left(t-\frac{x-x_{m}}{u_{0}}\right)}{2 \sqrt{\pi u_{0} \alpha\left(x-x_{m}\right)}} f_{m} \exp \left[-\frac{k}{u_{0}}\left(x-x_{m}\right)\right] U\left(t-\frac{x-x_{m}}{u_{0}}\right)\right. \\
& \cdot U\left(x-x_{m}\right) \sum_{n=-\infty}^{\infty}\left\{\exp \left[-\frac{u_{0}\left(y-y_{m}-2 n b\right)^{2}}{4 \alpha\left(x-x_{m}\right)}\right]\right. \\
& \left.\left.+\exp \left[-\frac{u_{0}\left(y+y_{m}-2 n b\right)^{2}}{4 \alpha\left(x-x_{m}\right)}\right]\right\}\right)
\end{aligned}
$$

With careful selection of point source strengths and locations, many realistic sources can be represented. This technique will be used in a later section to consider the excess temperature from a line source at some angle to the shore. 
The time dependence is the same in all the cases considered in the previous section. The time rate of change of the excess temperature at any point is proportional to the time rate of change of the function $q\left(t-\frac{x-x_{0}}{u_{0}}\right)$ and, therefore,

$$
\begin{aligned}
\frac{\partial(\Delta T)}{\partial t} \propto & U\left(t-\frac{x-x_{0}}{u_{0}}\right) \frac{d q}{d t}\left(t-\frac{x-x_{0}}{u_{0}}\right) \\
& +q\left(t-\frac{x-x_{0}}{u_{0}}\right) \delta\left(t-\frac{x-x_{0}}{u_{0}}\right) .
\end{aligned}
$$

The delta function in this equation is a result of the excess temperature front and has no real significance when calculating the time derivative. It will he disregarded so that

$$
\frac{\partial(\Delta T)}{\partial t} \propto U\left(t-\frac{x-x_{0}}{u_{0}}\right) \frac{d q}{d t}\left(t-\frac{x-x_{0}}{u_{0}}\right) .
$$

This form of the time rate of change is appropriate for any of the results in the previous section. For example, the time rate of change of excess temperature at any point from multiple point sources is

$$
\begin{array}{r}
\frac{\partial(\Delta T)}{\partial t}=\sum_{m=1}^{M}\left(\frac{U\left(t-\frac{x-x_{m}}{u_{0}}\right)}{2 \sqrt{\pi u_{0} \alpha\left(x-x_{m}\right)} \frac{\partial q}{\partial t}\left(t-\frac{x-x_{m}}{u_{0}}\right) f_{m} \exp \left[-\frac{k}{u_{0}}\left(x-x_{m}\right)\right]}\right. \\
\cdot U\left(x-x_{m}\right) \sum_{n=-\infty}^{\infty}\left\{\exp \left[-\frac{u_{0}\left(y-y_{m}-2 n b\right)^{2}}{4 a\left(x-x_{m}\right)}\right]\right. \\
\left.\left.+\exp \left[-\frac{u_{0}\left(y+y_{m}-2 n b\right)^{2}}{4 a\left(x-x_{m}\right)}\right]\right\}\right) .
\end{array}
$$


Results for a straight coastline of an ocean or lake are easily obtained from the river results if the flow is uniform and longshore. In this case, the far boundary can be moved to infinity and the boundary conditions are:

$$
\left.\frac{\partial(\Delta T)}{\partial y}\right|_{y=0}=\left.\Delta T\right|_{x=-\infty}=\left.\Delta T\right|_{y=\infty}=0 .
$$

For the Green's function to satisfy these conditions, only a single image source located at $y=-y^{\prime}$ is required, and the Green's function becomes

$$
\begin{aligned}
G\left(x, y, x^{\prime}, y^{\prime}\right)= & \frac{2 \sqrt{\pi}}{a \sqrt{x-x^{\prime}}} U\left(x-x^{\prime}\right) \\
& \cdot\left\{\exp \left[-\frac{a^{2}\left(y-y^{\prime}\right)^{2}}{4\left(x-x^{\prime}\right)}\right]+\exp \left[-\frac{a^{2}\left(y+y^{\prime}\right)^{2}}{4\left(x-x^{\prime}\right)}\right]\right\} .
\end{aligned}
$$

This is simply the $n=0$ term in Equation (13). Therefore, the solution for a coastal situation can be obtained for any of the three cases in Section II by merely considering the $n=0$ term in the respective solutions. For example, the solution for the excess temperature from a point source is

$$
\begin{aligned}
T(x, y, t)= & \frac{q\left(t-\frac{x-x_{0}}{u_{0}}\right)}{2 \sqrt{\pi u_{0} \alpha\left(x-x_{0}\right)}} \exp \left[-\frac{k}{u_{0}}\left(x-x_{0}\right)\right] U\left(t-\frac{x-x_{0}}{u_{0}}\right) U\left(x-x_{0}\right) \\
& \cdot\left\{\exp \left[-\frac{u_{0}\left(y-y_{0}\right)^{2}}{4 \alpha\left(x-x_{0}\right)}\right]+\exp \left[-\frac{u_{0}\left(y+y_{0}\right)^{2}}{4 \alpha\left(x-x_{0}\right)}\right]\right\}
\end{aligned}
$$

COMPUTATION OF EXCESS TEMPERATURE BY COMPUTER

A computer program TWOD has been written in FORTRAN IV to calculate excess temperature and time rate-of-change of excess temperature 
using the results obtained in previous sections. A listing of TWOD is given in Appendix A. Because some of the results derived above are too general for efficient programming, the program is limited to specific useful situations, as described below.

The source strength as a function of time is taken to be

$q(t)=q_{0}\left[1-\exp \left(-t / \tau_{1}\right)\right]\left(1-U\left(t-t_{2}\right)\left\{1-\exp \left[-\left(t-t_{2}\right) / \tau_{2}\right]\right\}\right)$.

This form for the source strength is fairly versatile. If one is only concerned with the steady-state result, $t_{2}$ can be taken very large, and $\tau_{1}$ can be taken very small. This will give a step function for the transient source strength at time equal zero, as shown in Fig. 2a. To simulate plant shutdown, $\tau_{1}$ is small, $t_{2}$ is taken sufficiently large to insure steady-state, and $\tau_{2}$ is the shutdown e-folding time. This form for the source function is shown in Fig. $2 b$.

The method used for an arbitrary source distribution is programmed to approximate a Gaussian line source at an arbitrary angle to the shore. Since this form of the function has the capability to approximate a line source normal to the shore, the exact solution given in Section II is not programmed.

For a prescribed mean at $\left(x_{0}, y_{0}\right)$, standard deviation $\sigma$, and angle to shore $\theta$ (see Fig. 3), the line distribution is approximated by five point sources. To determine the strengths and locations of these point sources, the Gaussian is truncated at two standard deviations to either side of the mean, provided that the source has not yet intersected either shore. The line will intersect the near shore at a distance $-y_{0} / \sin \theta$ from the mean and will intersect the far shore at a distance $\left(b-y_{0}\right) / \sin \theta$ from the mean. To avoid creating point sources beyond the boundaries of the river, the line source will be truncated at the near shore at $\xi_{1}=-y_{0} / \sin \theta$, if $y_{0} / \sin \theta \leqslant 2 \sigma$. Similarly, the line source will be truncated at the far shore at $\xi_{2}=\left(b-y_{0}\right) / \sin \theta$, If $\left(b-y_{0}\right) / \sin \theta \leqslant 2 \sigma$. In all other instances, $\xi_{1}=-2 \sigma$ and $\xi_{2}=2 \sigma$. The line segment from $\xi_{1}$ to $\xi_{2}$ is divided into five equal intervals of width $\Delta$, so that 


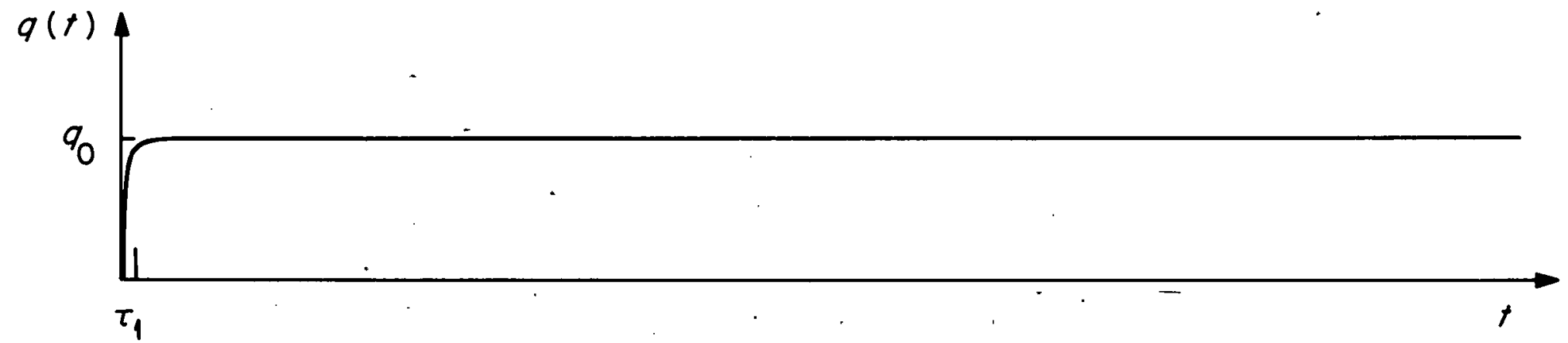

(a) STEP-FUNCTION APPROXIMATION FOR STEADY-STATE RESULTS

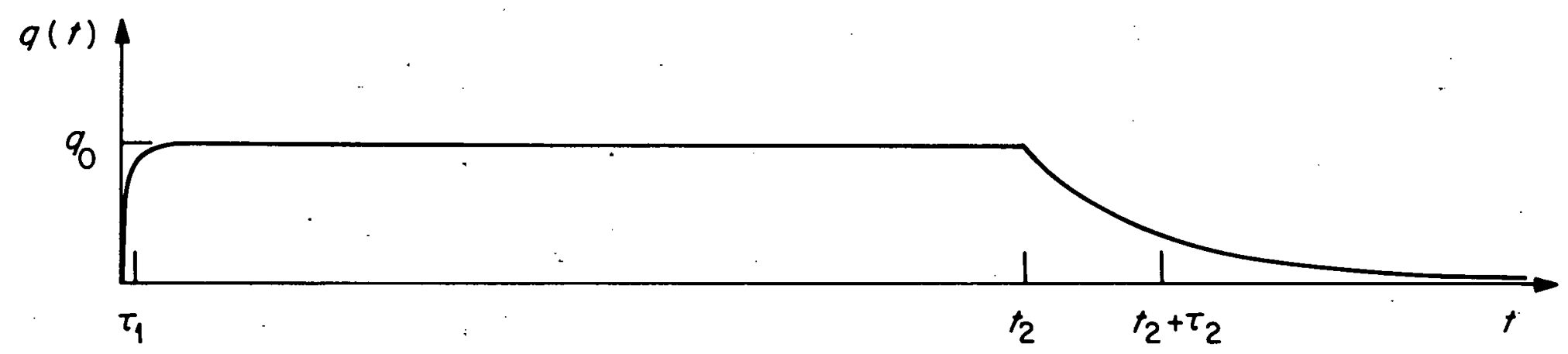

(b) SIMULATION OF SOURCE SHUT-DOWN FROM STEADY-STATE

Fig. 2. Examples of the transient source function $q(t)$ used in the program TWOD. 
ORNL-DWG $78-4853$

(a)

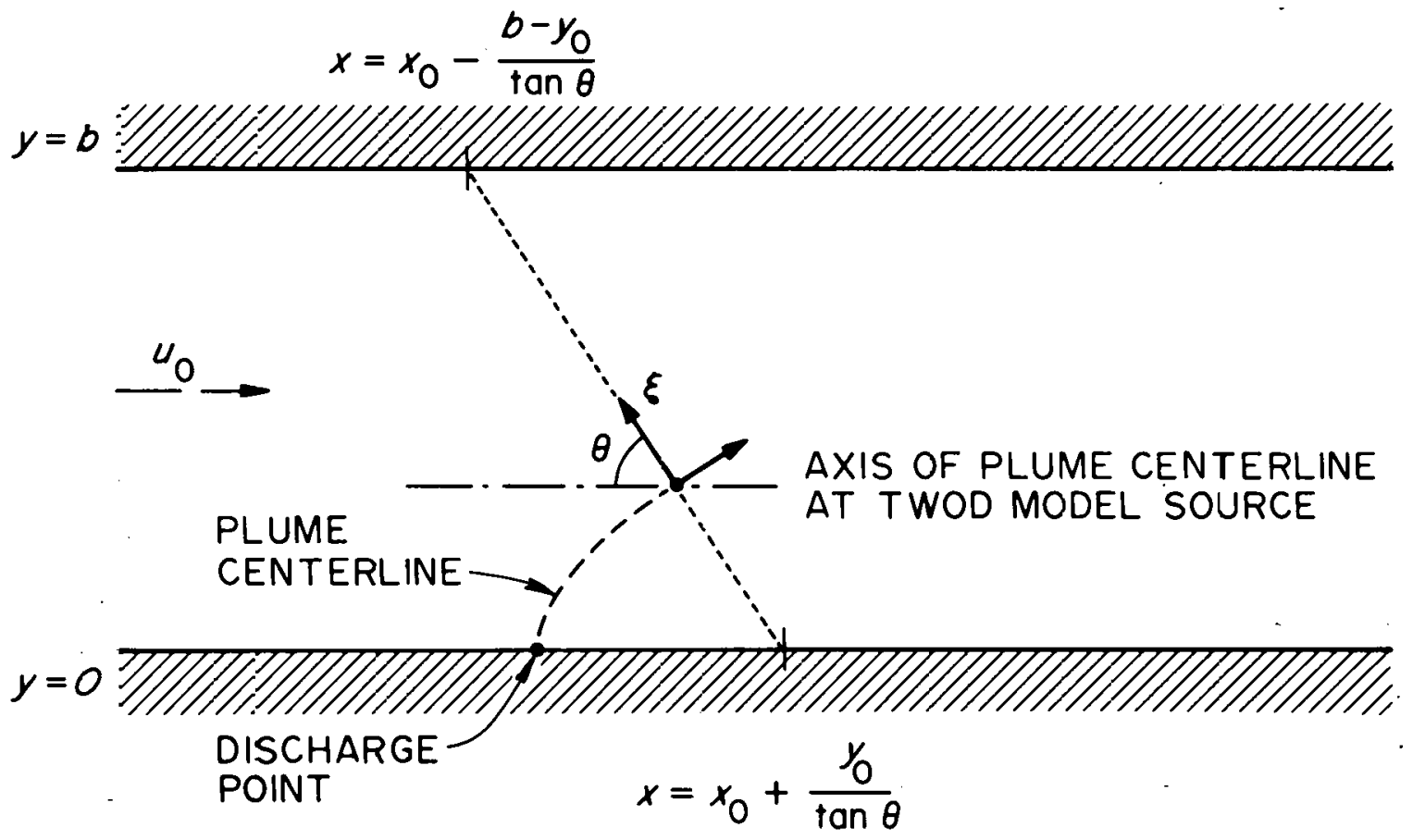

(bi

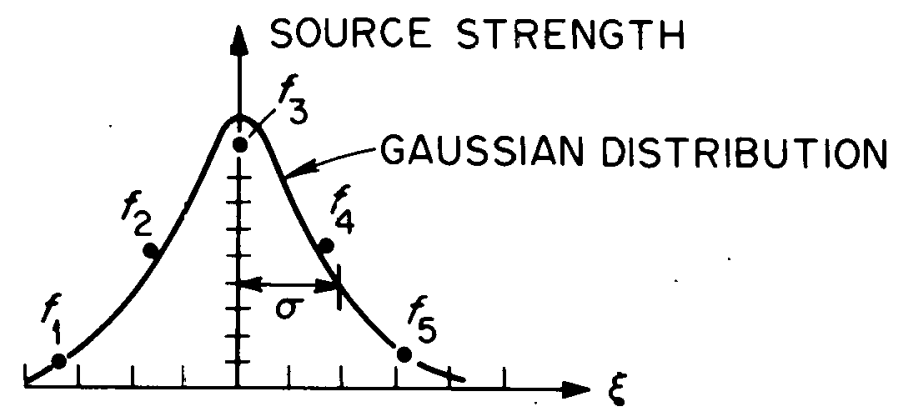

Fig. 3. Definition sketch for the approximation of a Gaussian line source. The angle of the line source with respect to the horizontal is $\theta$, and $\xi$ is the cross plume coordinate. 


$$
\Delta=\left(\xi_{2}-\xi_{1}\right) / 5
$$

A point source is located at the center of each of these five intervals,

$$
\begin{aligned}
& x_{m}=x_{0}-\left[\xi_{1}+(2 m-1) \frac{\Delta}{2}\right] \cos \theta, \\
& y_{m}=y_{0}+\left[\xi_{1}+(2 m-1) \frac{\Delta}{2}\right] \sin \theta,
\end{aligned}
$$

where $m$ goes from 1 to 5 . The strength of each point source, $f_{m}$, will be proportional to the total strength of the Gaussian source over a particular interval $\Delta$, so that

$$
f_{m} \propto \int_{\xi_{1}+(m-1) \Delta}^{\xi_{1}+m \Delta} \exp \left[-\xi^{\prime 2} \sigma^{2}\right] d \xi^{\prime}
$$

Since the total source strength is specified by the constant $q_{0}$, all the point source strengths must be normalized by the total strength of the Gaussian over the interval $\xi_{1}$ to $\xi_{2}$. Performing the necessary integrations, the point source strength can be written

$$
f_{m}=\frac{\operatorname{erf}\left(\frac{\xi_{1}+m \Delta}{\sigma}\right)-\operatorname{erf}\left(\frac{\xi_{1}+(m-1) \Delta}{\sigma}\right)}{\operatorname{erf}\left(\frac{\xi_{2}}{\sigma}\right)-\operatorname{erf}\left(\frac{\xi_{1}}{\sigma}\right)^{i}} .
$$

The capability for representing an arbitrary source by a number of point sources is also incorporated in the TWOD program. The user simply specifies the strength and location of each point source, as input, and the program automatically calculates the excess temperature from all of these sources, using Eq. (27). (The program is dimensioned for a maximum of 10 point sources.) This feature is particularly useful for calculating the effects from multiple discharges. 
INPUT AND OUTPUT INFORMATION FOR COMPUTER ANALYSIS

The input parameters are defined so that the computer program TWOD contains no dimensional constants. Therefore, the program is not limited to any specific system of units. However, it is important to use consistent units for all input data. The output will be in the same units as the input. Input specifications are shown in Table 1.

If the multiple point source option is used, there should be one card for each point source. For example, if five point sources are used, there should be a total of ten input cards.

The input parameters $\sigma$ and $\theta$ are required only for the Gaussian line source. If the point source is selected, whatever values of $\sigma$ and $\theta$ that are entered will be ignored. The input parameter $x_{\text {max }}$ is optional. It is used to specify a downstream value at which calculations are terminated. If the fifth card is left blank, calculations will continue to the edge of the plume, which is at $x=x_{0}+u_{0} t$ (for the specified values of $x_{0}, u_{0}$, and $\left.t\right)$. Usually, the unit of time used for the input variables will be seconds. If this is the case and the time rate-of-change of excess temperature is requested, the values of the output could be quite small (particularly if $\tau_{2}$ is large). Therefore, it might be desirable to multiply the input value for $q_{0}$. by 60 (3600) and thereby produce an output in degrees per minute (degrees per hour), rather than degrees per second.

To run multiple cases, successive sets of input cards may be placed one after the other.

Printed output will consist of an array of values for either the excess temperature or the time rate-of-change of the excess temperature. Values are listed in the cross-stream ( $y$ ) direction at intervals of one-tenth of the river width and in the downstream direction at multiples of the river width $(b, 2 b, 3 b$, etc.). If the plotting option is requested, a finer grid is used for calculations, but the printout will be the same. The contour plots produced will be $10 \mathrm{in.} \mathrm{high} \mathrm{and} 24 \mathrm{in.}$ long and will show five contours. The values of these contours are generated internally and will be listed at the bottom of the printout. No contour values will be given on the plots. 
Table 1. Input for TWOD

\begin{tabular}{|c|c|}
\hline Columns & $\begin{array}{l}\text { Data } \\
\text { (right justified in assigned columns) }\end{array}$ \\
\hline & First card \\
\hline & [Format (20A4)] \\
\hline \multirow[t]{3}{*}{$1-80$} & Any title or identification. \\
\hline & Second card \\
\hline & [Format (3I5)] \\
\hline $1-5$ & $\begin{array}{l}\text { Source function type: }=0 \text { for Gaussian line source; }=1 \text { for } \\
\text { point source; }=n(n=2-10) \text { for } n \text { arbitrary point sources. }\end{array}$ \\
\hline $6-10$ & Plot: $=1$, if contour plots are desired. \\
\hline $11-15$ & $\begin{array}{l}\text { Time-derivative: }=1 \text {, if the time rate-of-change of excess } \\
\text { temperature is desired rather than excess temperature. }\end{array}$ \\
\hline \multicolumn{2}{|r|}{ Third card } \\
\hline \multicolumn{2}{|r|}{ [Format $(6 \mathrm{~F} 10.0)]$} \\
\hline $1-10$ & $t$ - time at which excess temperature is to be calculated. \\
\hline $11-20$ & $\begin{array}{l}q_{0}-\text { total source strength, equal to the product of the } \\
\text { excess temperature of the discharge and the discharge flow } \\
\text { rate divided by the river depth (length squared-degrees/time. }\end{array}$ \\
\hline $21-30$ & $t_{2}-$ plant shutdown time. \\
\hline $31-40$ & $\tau_{1}-$ start-up e-folding time. \\
\hline $41-50$ & $\tau_{2}$ - shutdown e-folding time. \\
\hline $51-60$ & $\begin{array}{l}x_{0}-\text { downstream coordinate of polnt source or mean of } \\
\text { Gaussian line source. }\end{array}$ \\
\hline \multicolumn{2}{|r|}{ Fourth card } \\
\hline \multicolumn{2}{|r|}{ [Format $(7 \mathrm{~F} 10.0)]$} \\
\hline $1-10$ & $\begin{array}{l}y_{0}-\text { cross-stream coordinate of point source or mean of } \\
\text { Gaussian line source. }\end{array}$ \\
\hline $11-20$ & $\alpha-$ eddy diffusivity. \\
\hline $21-30$ & $u_{0}-$ ambient river flow. \\
\hline $31-40$ & $\begin{array}{l}k \text { - the surface heat exchange coefficient divided by the } \\
\text { product of the density, the heat capacity, and the depth. } \\
\text { This should have dimensions of time }{ }^{-1} \text {. }\end{array}$ \\
\hline $41-50$ & $b$ - width of the river. \\
\hline $51-60$ & $\begin{array}{l}\sigma-\text { standard deviation (temperature e-folding width) of the } \\
\text { line source. }\end{array}$ \\
\hline $61-70$ & $\begin{array}{l}\theta-\text { the angle of the line source with respect to. shore } \\
\left(=0^{\circ}: \text { discharge centerline is normal to shore; }=90^{\circ}:\right. \\
\text { discharge centerline is parallel to shore }) \text {. }\end{array}$ \\
\hline \multicolumn{2}{|r|}{ Fifth card } \\
\hline \multicolumn{2}{|r|}{ [Format $(7 F 10.0)]$} \\
\hline $1-10$ & $\begin{array}{l}x_{\max }-\text { maximum value of downstream coordinate (optional). } \\
\text { Sixth card-fifteenth card }\end{array}$ \\
\hline \multicolumn{2}{|r|}{$\begin{array}{l}\text { [Format ( } 3 F 10.0)] \\
\text { (used only for multiple sources) }\end{array}$} \\
\hline $1-10$ & $x_{m}$ - downstream coordinate of $m$ th point source. \\
\hline $11-20$ & $y_{m}$ - cross-streamicoordinate of $m$ th point source. \\
\hline $21-30$ & $\begin{array}{l}f_{m}-\text { source strength of } m \text { th point source, which should have } \\
\text { dimensions of length squared-degrees/time. }\end{array}$ \\
\hline
\end{tabular}


To demonstrate the use of the program TWOD, an example has been run; the results are reproduced here. The example consists of three cases for the same physical conditions, but at three different times during a plant shutdown. The values for the input parameters are listed in Table 2. The ambient conditions are a river velocity of $3.0 \mathrm{ft} / \mathrm{sec}$, a river width of $600 \mathrm{ft}$, and a river depth of $20 \mathrm{ft}$.

Table 2. Input parameters for three executions of the program TWOD

\begin{tabular}{|c|c|c|c|}
\hline \multirow{2}{*}{ Variable } & \multicolumn{3}{|c|}{ Data supplied } \\
\hline & Case 1 & Case 2 & Case 3 \\
\hline Source function ${ }^{a}$ & 0 & 0 & 0 \\
\hline Plot $b$ & 1 & 1 & 0 \\
\hline Time-derivative ${ }^{b}$ & 0 & 0 & 1 \\
\hline$t(\mathrm{sec})$ & 7,200 & 10,800 & 12,600 \\
\hline 90 & $\begin{array}{c}3,000 \\
\left(F^{\circ} \cdot \mathrm{ft}^{2} / \mathrm{sec}\right)\end{array}$ & $\begin{array}{c}3,000 \\
\left(F^{\circ} \cdot \mathrm{ft}^{2} / \mathrm{sec}\right)\end{array}$ & $\begin{array}{c}180,000 \\
\left(F^{\circ} \cdot \mathrm{ft}^{2} / \mathrm{min}\right)\end{array}$ \\
\hline$t_{2}(\mathrm{sec})$ & 7,200 & 7,200 & 7,200 \\
\hline$\tau_{1}(\mathrm{sec})$ & 10 & 10 & 10 \\
\hline$\tau_{2}(\mathrm{sec})$ & 1,800 & 1,800 & 1,800 \\
\hline$x_{0}(f t)$ & 0 & 0 & 0 \\
\hline$y_{0}(f t)$ & 100 & 100 & 100 \\
\hline$\alpha\left(f t^{2} / \mathrm{sec}\right)$ & 2 & 2 & 2 \\
\hline$u_{0}(f t / s e c)$ & 3 & 3 & 3 \\
\hline$k\left(\sec ^{-1}\right)$ & 0 & 0 & 0 \\
\hline$l(\Gamma \mathrm{L})$ & 600 & 600 & 600 \\
\hline$\sigma(f t)$ & 20 & 20 & 20 \\
\hline$\theta($ deg $)$ & 70 & 70 & 70 \\
\hline$x_{\max }(\mathrm{ft})$ & 20,000 & 22,000 & Blank \\
\hline
\end{tabular}


At some point along a shore of the river, a power plant is discharging cooling water normal to the shore with an excess temperature of $20^{\circ} \mathrm{F}$ and at a rate of $3000 \mathrm{cfs}$. Away from the point of discharge, the jet spreads and loses some momentum.

At $100 \mathrm{ft}\left(y_{0}\right)$ from shore, the jet has lost most of its initial momentum, and, at the same time, has been turned through an angle of $70^{\circ}$ $(\theta)$ by the ambient flow. The temperature distribution across the jet can be represented by a Gaussian with a standard deviation of $20 \mathrm{ft}(\sigma)$. This is the beginning of the far field, and this physical description of the jet (plume) at this point is the boundary conditions for the TWOD far-field model.

The first case is at a time of $7200 \mathrm{sec}(2 \mathrm{hr})$; steady-state conditions exist and plant shutdown is imminent. The printed output for this case is given in Fig. 4, and the plotted result is shown in Fig. 5. As expected, the maximum excess temperatures are found near the source. The second case is at a time of $10,800 \mathrm{sec}, 1 \mathrm{hr}$ after plant shutdown has begun. The discharge temperature has decreased, and the warm water near the source has been advected downstream. This can be seen in the printed output (Fig. 6) or the plotted output (Fig. 7). The warmest water is in a "pool" $6000 \mathrm{ft}$ downstream. This pool is cooling, through diffusion, as it is being swept downstream at a rate of $3.0 \mathrm{ft} / \mathrm{sec}\left(u_{0}\right)$. Surface heat exchange was not included in this calculation since its effect would be negligible in this case. For instance, if the surface heat exchange coefficient was assumed to be $3 \mathrm{Btu} / \mathrm{hr} \cdot \mathrm{ft} \mathrm{t}^{2} \cdot{ }^{\circ} \mathrm{F}$, a parcel of heated water would have to travel six miles downstream before surface heat transfer could produce a $2 \%$ temperature change. The final case gives the time rate-of-change of excess temperature at $1.5 \mathrm{hr}$ after the start of plant shutdown. The results are shown as printed output in Fig. 8. All values are negative, since the temperature is decreasing. The greatest rate-of-change is approximately $-0.13^{\circ} \mathrm{F} / \mathrm{min}\left(-7.8^{\circ} \mathrm{F} / \mathrm{hr}\right)$, $15,600 \mathrm{ft}$ downstream along the near shore. The rate-of-change is zero beyond 16,200 ft downstream, since insufficient time has elapsed for changes at the source to be advected to these distances. 
THO DIMPNSIONAL TRANSIZ!: PAR-PIELD ANALTSIS

EXAMPLE: STEADY-STATE TEMPQRATORE IN DEGREES $P$

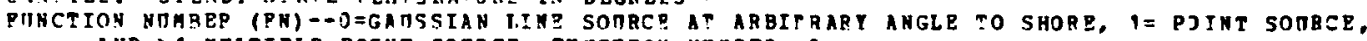

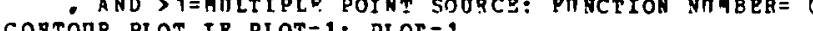

IISE DER IVATIVE OP O PUNETION IF QR=1: QR=0

$T=720$.

IHAT $=2.000000$ E 04 SIGSA $=20.0$ THETA $=70.00$

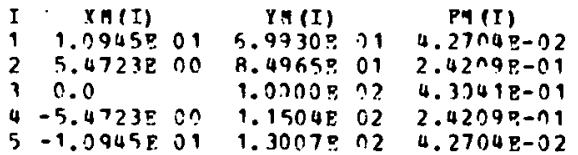

\begin{tabular}{|c|c|c|c|c|c|c|c|c|c|c|c|c|}
\hline & $\mathrm{Y}$ & 0 & א? & 127 & 190 & 240 & 300 & 360 & 420 & 493 & 540 & 600 \\
\hline & & & & & & & & & & & & \\
\hline $\begin{array}{l}600 \\
12 \pi 0\end{array}$ & 1 & 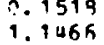 & $\begin{array}{l}5.6754 \\
6.0542\end{array}$ & $\begin{array}{r}10.3576 \\
8.4400\end{array}$ & $\begin{array}{l}3.5019 \\
1.5793\end{array}$ & $\begin{array}{l}0.0305 \\
0.0395\end{array}$ & $\begin{array}{l}0.3009 \\
0.3001\end{array}$ & $\begin{array}{l}0.0050 \\
0.0300\end{array}$ & $\begin{array}{l}0.0000 \\
0.0000\end{array}$ & $\begin{array}{l}0.0000 \\
0.0000\end{array}$ & $\begin{array}{l}0.0000 \\
0.0000\end{array}$ & $\begin{array}{l}0.0303 \\
0.0000\end{array}$ \\
\hline $180 ?$ & $i$ & 2.2724 & .8232 & 7.2659 & 2.2794 & ח.1787 & 0.0035 & 1.0001 & 8.0 & 0.0 & 0.0000 & 0.0503 \\
\hline 2470 & & 3. & 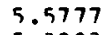 & 9.4771 & 2.6675 & 0.3805 & $0.018 \mathrm{~A}$ & .0003 & .0000 & & 0.0000 & 0.0000 \\
\hline $300 n$ & & 3.7 & $19 n 3$ & 5.9027 & 2.8743 & 0.5946 & 0.05 & .0019 & 00 & 0. & & 000 \\
\hline 3500 & 1 & 4.1515 & 2526 & 5.4770 & 2.7789 & 0.7929 & .1027 & 0.0063 & .0002 & & 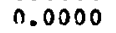 & .0 \\
\hline 42 & 1 & 4.4267 & 1 & 5.1517 & 3.0257 & 0.9658 & .1 & 8 & .0 & & & 0.0000 \\
\hline 4ann: & & 4.50 & 9 & 4.9 & 3.0 & .1 .1 & 2.2 & .0 & 0.0 & & & 0.0000 \\
\hline 5400 & 1 & 4.7242 & .99 & 4.6932 & 3.0360 & 1.2350 & 0.3 & 19 & .0 .045 & & 0.0 & 0.0203 \\
\hline 6000 & & 4.7942 & .9281 & 4.5372 & 3.0225 & 1.3372 & 0.3840 & .0 & 0.0 & 0. & & 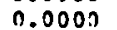 \\
\hline & & 4.9314 & .86 & & 3.1 & 1.4 & & & & & & \\
\hline $72 \subseteq 0$ & $i$ & 4.84 & 8 & 4.2 & 2.9 & 1.4 & ${ }^{2}$ & & 5 & & & 00 \\
\hline 78r. & 1 & 4.94 & 4.7 & 4.2 & 2.9 & 1.5547 & 7.5 & & 0.0 .308 & & & 0.0001 \\
\hline Ruกn & 1 & 4.8260 & $.7 n$ & 4.1245 & 2.9455 & 1.6062 & 0.6496 & 27 & .0 & & 0. & 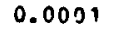 \\
\hline 9300 & 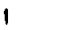 & 4.9617 & 6 & 4.0558 & 2.9274 & 1.6504 & 2 & & & & & \\
\hline 9603 & I & 4.77 & $\because$ & 3.9 & .9 & & & & & & & \\
\hline is. & & 4.73 & & 3.9 & 2.9 & 1.7 & & & & & & 008 \\
\hline 10900 & & 4.595 & .50 & 3.8914 & 2.8 & 1.7 & $n$. & & 2 & & & 013 \\
\hline 11400 & & 4.5 & 4 & 3.8 & & & & & & & & \\
\hline $20 n \pi$ & i & 4.61 & .4 & 3.8 & 2.8 & 1.8 & & & & & & \\
\hline & $i$ & 4.565 & . & & & & & & & & & \\
\hline ?? & $i$ & 4.52 & 4.3 & & & 1.9 & & & & & & 553 \\
\hline 13890 & $r$ & 4.4775 & 4.2 & 3.5 & 2.9 & 1.8 & & & & & & 0070 \\
\hline 14400 & 1 & 4.43 & .? & 3.5 & 2.9 & $1 . \mathrm{A}$ & & & & & & \\
\hline & 1 & 4.3 & & & & & & & & & 16 & 3 \\
\hline & 1 & 4.3 &. & 3.6 & & $\varphi^{\prime}$ & & & & & & \\
\hline 16200 & 1 & 4. 302 & 4.1 & 3.5 & 2.7 & 1.9 & & & & & 0.0 & 0.0 \\
\hline & 1 & & & & & 1. & & & & & & \\
\hline & 1 & 4.21 & 4.0 & 3.5 & 2.7 & 1.93 & & & 0. & & & 0.0251 \\
\hline & 1 & & & & & 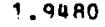 & & & & & 9.0 & .02 \\
\hline & 1 & 4. & 3.9 & 3.4 & 2.7 & 1.95 & 1. & & 0.3 & & 0.0 & 0.0342 \\
\hline $1920 n$ & 1 & 4.0978 & 3.9 & 3.46 & 2.74 & 1.98 & 1.2 & & & & & 94 \\
\hline & & 593 & & 4 & 17.5 & 1.9729 & 1.2753 & 0.7329 & $n .3726$ & A2 & .0721 & 45 \\
\hline
\end{tabular}

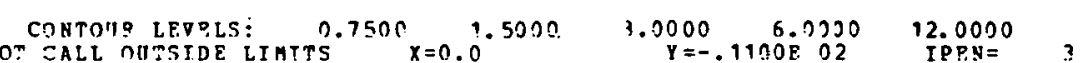

Fig. 4. Print-out of excess temperature for Case 1, steady-state (the input parameters are given in Table 1). 


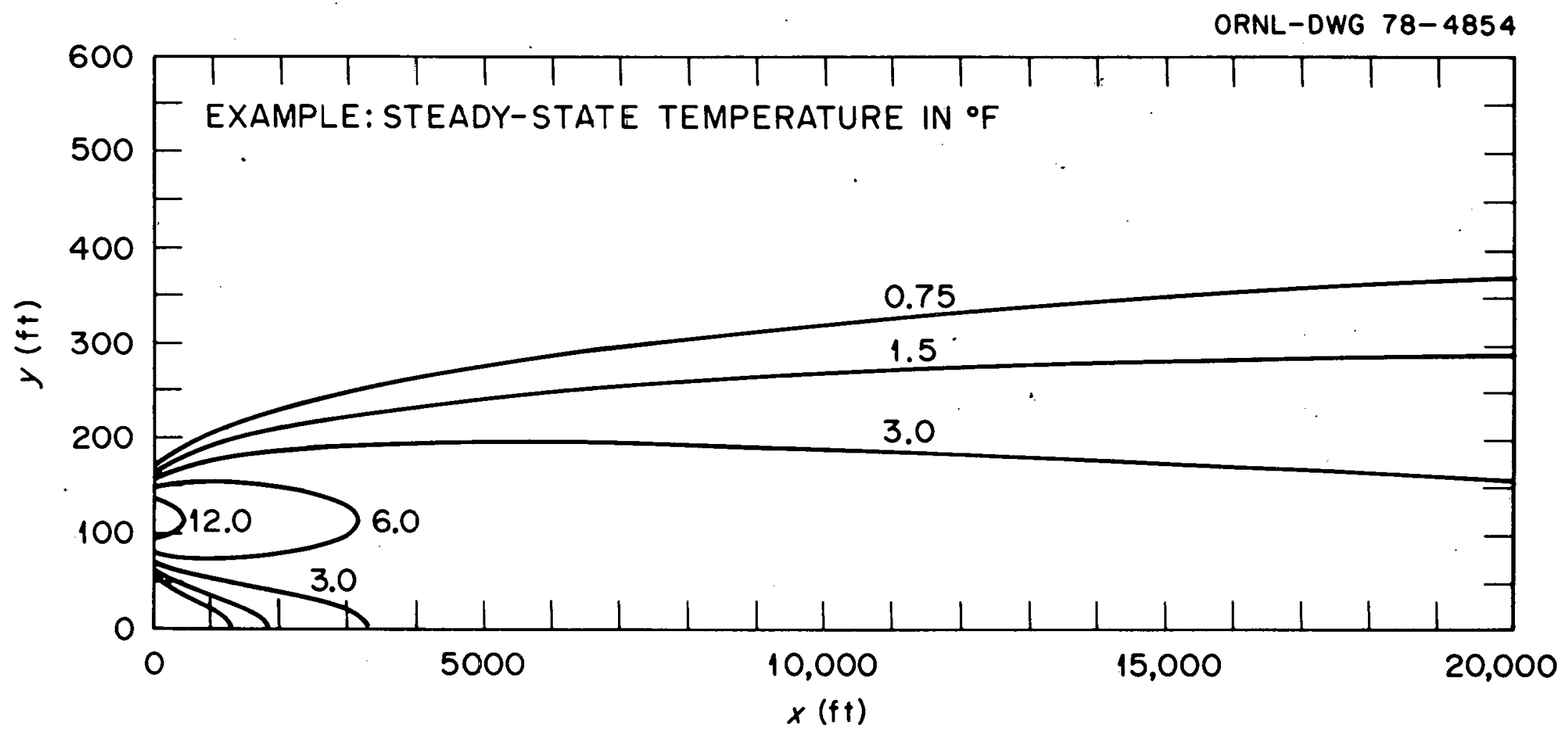

Fig. 5. Excess temperature isotherms for Case 1. 


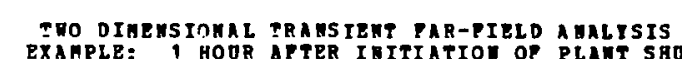

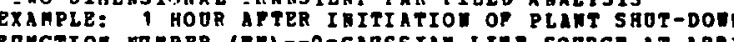

SOAG SOOBCE. CONTOOR PLOT IP PLOT=1: PLOT=1

OSE DERTVATIVE OF Q FONCTION IP QR=1: OK=0

$T=10890.000=3000.0 T 2=7200.0$ TAV1= $10 .$, TAO2* 1800.0 Y $0=0.0$ T0 $=100.0$

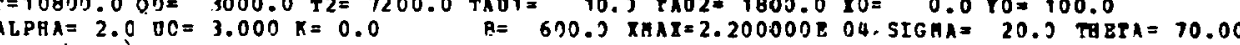

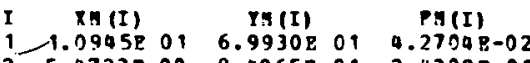

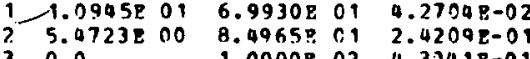

$0.0 \quad 1.0000802 \quad 4.33418-01$

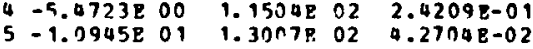

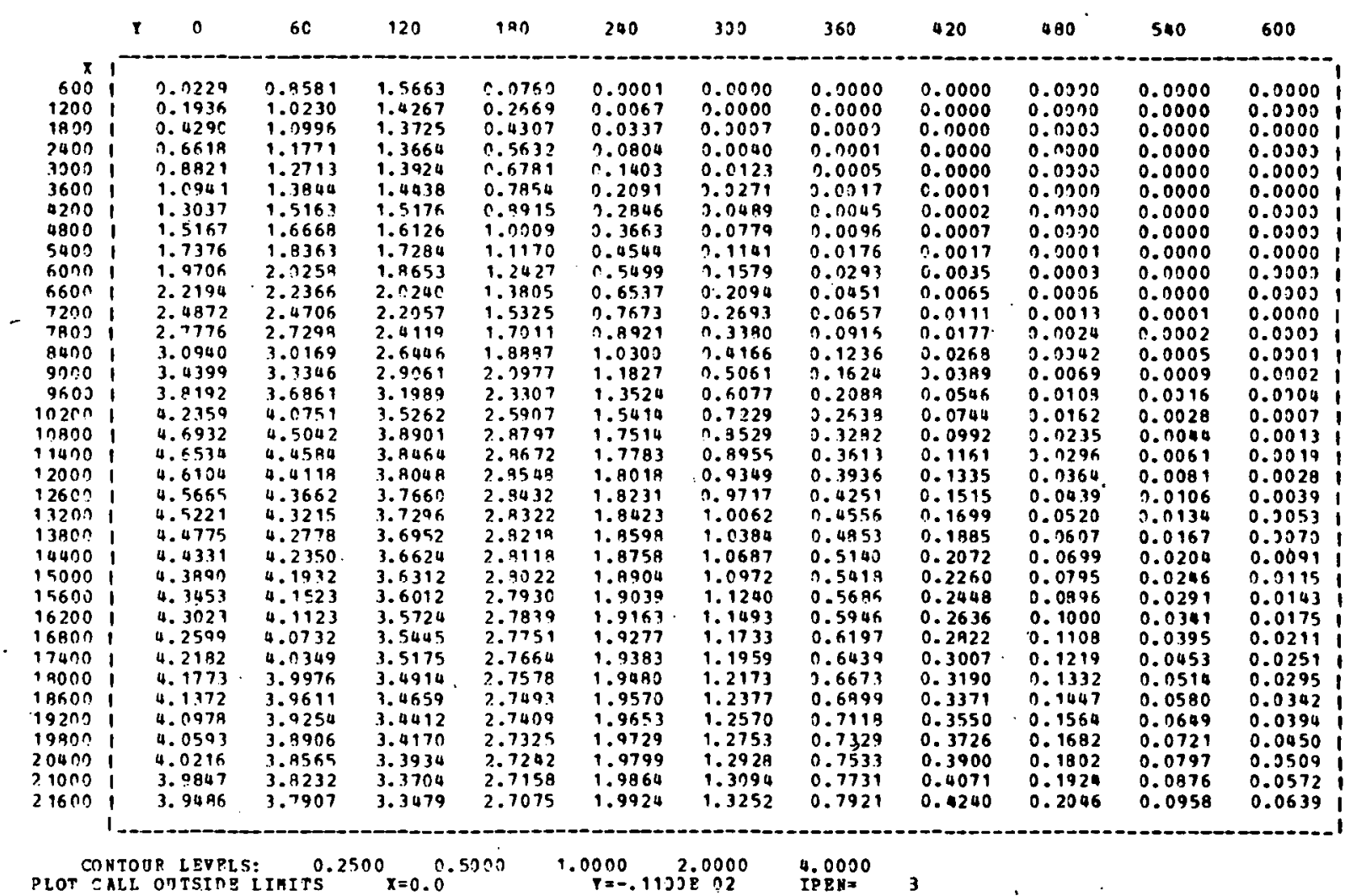

Fig. 6. Print-out of excess temperature for Case 2, plant shutdown (the input parameters are given in Table 1). 
ORNL-DWG 78-4855

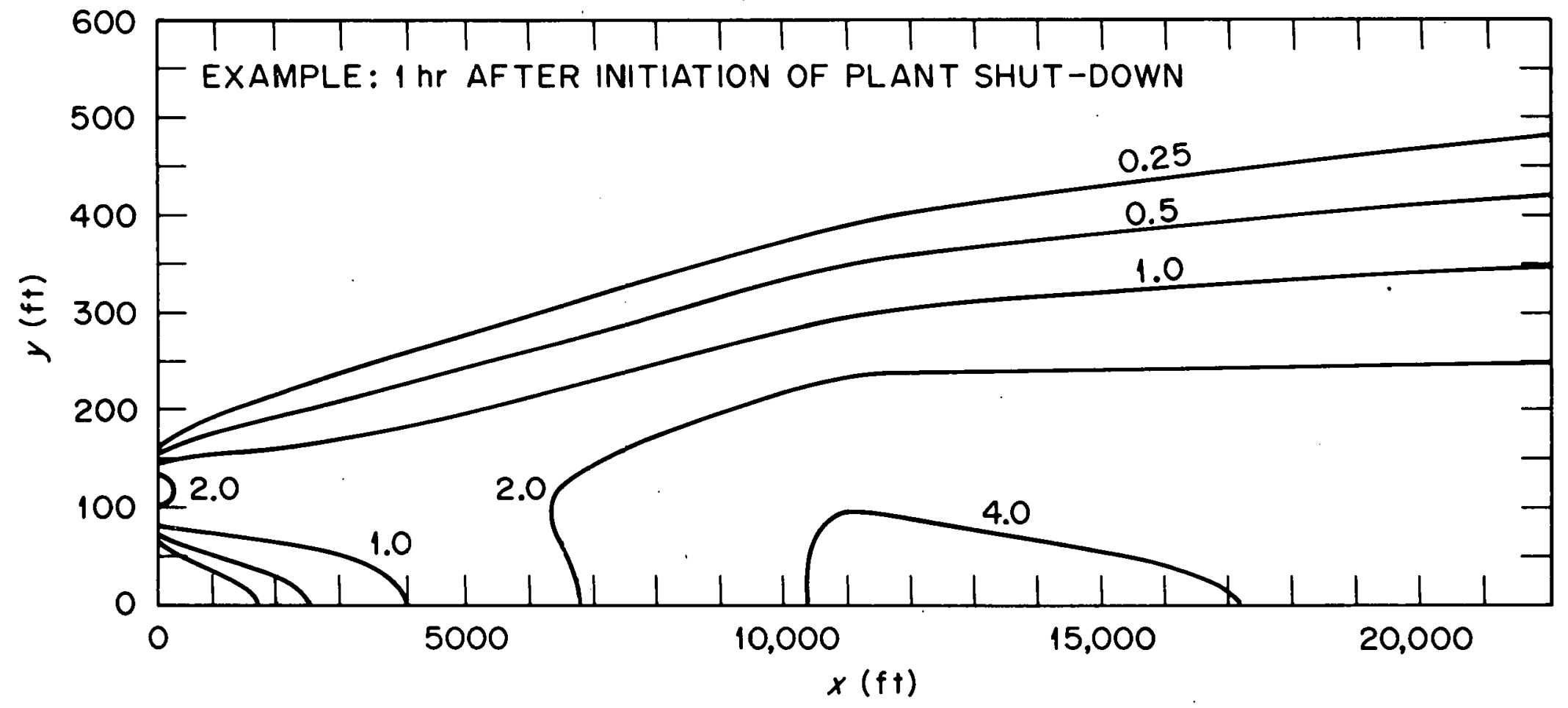

Fig. 7. Excess temperature isotherms for Case 2. 
TRO DI HENSIONAL TRANSIENT PAR-PIPID ANALYSTS

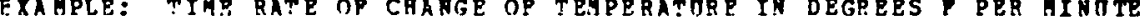

FIINCTION NUABER (PN) --O=GhUSSIAN LINE SOTRCE AT ARBIT BARY ANGLE TO SHORE, $1=$ PJINT SOOBCB.

- AND > T= RULTIDLE POINT SOTRCE: PIINCTION RUMBER= 0

CONTCUR PLOT IP PLOT= 1: PLOT $=0$

ESE DER I HATIYE OP Q PUHETIOH IP QR=1: QR=1

$T=12500.0 Q Q=180000.0 \mathrm{~T} 2=7200.0 \mathrm{TAII}=10.2 \mathrm{TMO} 2=1800.0 \times \mathrm{N}=0.0 \times 0=100.0$

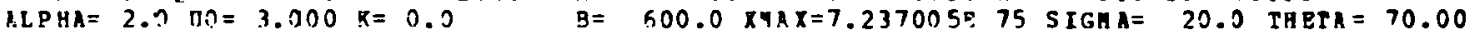

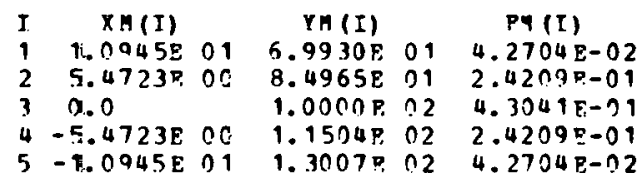

\begin{tabular}{|c|c|c|c|c|c|c|c|c|c|c|c|c|}
\hline & 8 & 0 & 60 & 120 & 190 & 240 & 300 & 360 & 420 & 480 & 540 & $600^{\prime}$ \\
\hline & & & & & & & & & & & & \\
\hline 600 & 1 & $c .0003$ & 0105 & & & n00? & 6002 & 00200 & nn? & -0.0.00 & & 003 \\
\hline $12 n n$ & i & . & & & & & & & & & & \\
\hline 1900 & i & -9.0053 & .01 & & & & & & & & & \\
\hline $2.4 \cap 0$ & 1 & $-1)$ & & 0 & 0 & & & & & & & \\
\hline 3000 & $i$ & -3.0108 & n. & & & & & & & & & \\
\hline $360 \mathrm{C}$ & 1 & -0. & & $-n$. & -0.0 & $-n$. & $-i$. & & & & & \\
\hline & $i$ & $-n$ & & -0 & & & & & & & & \\
\hline 900 & $i$ & -3.9 & -0 & $=0$. & -0. & & -0. & -0 . & & & & \\
\hline 5400 & 1 & -0.0213 & 0 & -0.1 & $-n . ?$ & -0. & -0.0 & -0 . & -0. & & & \\
\hline $60 n 0$ & 1 & $-n$ & - & -0.0 & -0. & -0. & -0.0 & & & & & \\
\hline fas on & $i$ & $-n$ & & -0. & -0. & -3. & -2 & -0 . & -0 & & & \\
\hline 7200 & $i$ & & & & -2. & & & & & & & \\
\hline $78 \mathrm{CO}$ & 1 & $-n$ & 2 & -0. & -0.9 & -0. & -3 & & & & & \\
\hline R4no & $i$ & -0.0 & -0. & 324 & $-r . n$ & -0. & -3. & & & & & \\
\hline 9000 & 1 & -9 & & & -0.1 & & -0. & & & & & \\
\hline 00 & 1 & & -0 . & -0 & -0.3 & -0 & & & & & & \\
\hline 20 & 1 & & & & -9. & -2. & & & & & & \\
\hline 9.00 & 1 & -0. & & $-n$ & -0 . & -0. & & & & & & \\
\hline 40 & 1 & -0. & -0 & -0 & -0. & -3 & -0. & & & & -0 & \\
\hline 0 & 1 & -0.1 & -0 & -0 & -0. & & -3. & & & & & \\
\hline & $i$ & $-n$. & $-n$. & -0 & -3. & -0 & -0. & & & & -0 & \\
\hline 200 & 1 & -0 & & -0. & -0. & & & & & & & \\
\hline $9 \mathrm{co}$ & 1 & $-2 . !$ & -0 & -3 & $-0 . n$ & & -0 & & & & & \\
\hline 1000 & 1 & -2.1 & & & -0.0 & & & & & & & \\
\hline & 1 & -0. & & & -1 & $-n .0$ & -0.0 & & -0 & & -9 & -0.3 \\
\hline & 1 & -2.1 & $-n$ & -0. & -0.08 & -0. & $-n .0$ & & & & & \\
\hline & $i$ & $-n$. & $-n$. & -0 & -0.94 & -0. & $-n .09$ & -0 & $-0 . n 0$ & -0 & -0 & -0 \\
\hline & & & & & & & 1 & & & & 0. & \\
\hline
\end{tabular}

IHCOO2I STOP 9969

Fig. 8. Print-out for Case 3, time rate-of-change of excess temperature in Fahrenheit degrees per minute (the input parameters are given in Table 1). 
An analytic solution has been presented for the advective diffusion equation in two dimensions. This solution treats an arbitrary transient source exactly and approximates an arbitrary spatial source distribution. With the associated computer code TWOD, this solution provides an efficient method for dealing with transient power plant thermal output, particularly the cold shock problem.

This work does not, however, represent a universally applicable model. The simplifying assumptions required to obtain an analytic solution preclude its use for a number of cases. In particular, problems involving complex channel geometries or variable natural flows cannot adequately.be analyzed with this model. However, this model could be useful in such cases for both a scoping study as well as providing initial conditions to a more sophisticated numerical model. 


\section{REFERENCES}

R. W. Cleary and D. D. Adrian, "New Analytic Solutions for Dye Diffusion Equations," J. Environ. Eng. Div., Am. Soc. Civ. Eng., 99(EE3): 213-227 (June 1973).

L. Dresner, Steady Temperature Distributions in the Far-Field Region Obtained by Solution of the Equation of Convective Diffusion in Two Dimensions, ORNL/TM-4119, (April 1973).

P. M. Morse and H. Feshbach, Methods of Theoretical Physics, McGrawHill, New York, 1953.

D. A. Pilati, Transient Cooling of a One-Dimensional Thermal Plume and Its Application for Determining Cold Shock, ORNL/TM-4160 (May 1973).

A. J. Policastro and J. V. Tokar, Heated Effluent Dispersion in Large Lakes: State-of-the-Art of Analytical Modeling, ANL/ES-11, Argonne National Laboratory, Center for Environmental Studies (January 1972).

W. W. Sayre and F. M. Chang, "A Laboratory Investigation of Open-Channel Dispersion Processes for Dissolved, Suspended, and Floating Dispersants," U.S. Geol. Surv. Prof. Pap. 433-E (1968).

G. T. Yeh and Y. J. Tsai, "Analytic Three-Dimensional Transient Modeling of Effluent Discharges," Water Resour. Res. 12(3): 533-540 (1976). 
APPENDIX A

FORTRAN-IV FROGRAM "TWOD" 


\section{PAGES 29 to 30 WERE INTENTIONALLY LEFT BLANK}


PROGRAR THOD TROD

TWO-D MAIN PROGRAM

TWO-DIMENSIONAL TRANSIENT PAR-FIELD THERMAL ANALYSIS "THOD" DITH OPTIONAL CONTOUR PLOT

PROGRAG AUTHOP: A J NITTEN, ENERGI DIVISION, OAK RIDGE NATIONAL LABORATORY (ORNL) OAK RIDGE, TENNESSEE 37830

PROG RAMMED BY E C LONG, COMPUTER SCIENCES DIVISION, ORNL THOD

TROD

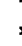

$\mathbf{I}$

T? IS SUgGESTEN THAT SPTS OP DATA CARDS BE NUMBERED

COLS. 7,3-80 ARE AVAILABLE ON ALL DATA CARDS

CARD 1 TITle 20 a

ANY SORT OP OUTPUT AND PLOTTING IDENTIPICATION

card 2 tentplotiok

PN IS PONCT TON TYPE

PN=0: GAUSSIAN LINE SOTRCE AT AN ARBITRARY ANGLE

$F N=1:$ FOINT SOURCE

PN>1: MULTIPLE POINT SOIIRCES

POR PLOT=1, PRONUCE CONTOUR PLOT

FOR OK=1, NSP DRRIVITAVE OF O FINCTION

card 3 ticoltzitaniltamzixo

T-- TTMF AT PHTCH BYCESS TEMPE RATORE IS $C$

CO--SOURC? STRENGTH, SHOULD HAVE DIMPNSICNS OP DEGRERS I IENGTH* *2/TIMP

T?--TIMF. AT RHICH PLANT SHUTS DORN

STAPT UP TIME IS ASSUMED TO EE ZRRO

TAU1--E-POLDING TIME POR PLANT START IJP

TAT2--P-POLDING TIDE POR PIANT SHOT DONN

XO--DONNSTREAM COORDINATE OP POINT SOIRCE OR MEAN OP GAUSSIAN LINE SOURCE

card 4 yolalphajoolkiblsigmaitheta

YO--CROSS STRFAM CONRDINATE OP POINT SODRCE OR MEAN OF GAUSSIAN LINE SOTRCE

AT, PHA--EDDY DIPEOSIVITY

TO- AMBIENT RIVER PLOR (ALKAYS POSITIVE)

R--STRFACB HEAT TRANSERR COEPPICIENT/(DENSITY*HEAT CAPACITY \#DEPTH) SHOTLD HAVE DIMENSIONS OF (1/TIME)

B--DINTH OF RIVER

SIGMA--TEMPERATTRE STANDARD DEVIATION OF LINE SOURCE (EODAL TO 1.44 *HALP-VALUE RIDTH)

TPP.TA--ANGLE OP LINE SODRCE VITH RESPECT TO THE SHORB

THETA=0 DEGRES DT SCHARGE CERTERLI NE NORAAL TO SHORE.

THETA $=90$ DEGREES DISCHARGE CENTERLINF PARALLEL TO SHOBR

Caso 5 xhat

$7 P 10.0$

YMAT IS DOHNSTRPAM DISTANCE AT WRICH CAICOLATIONS CEASE IP XMAX $=0.0$, XMAX IS SET TO LARGEST MACHINE NOHBER

cards fi-a,b-- tom(t) IYM(I) IPM(I)

$3 P 10.0$ $I=1, P N \quad(F O R \quad F N>1)$

XM(I) YM(I), E PM(I) ARE COORDINATPS AND STRENGTH OP OP POINT SOTRCE I

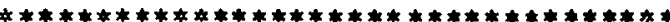

* PND OP INPUT INPORMATICN POR THOD*

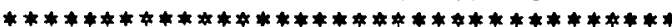

THOD

$T$ TMOD

TROD

TWOD

TWOD

TROD

TROD

*TWOD

\#THOD

*THOD

*THOD

*TNOD

*TROD

*THOD

*TROD

*TROD

*THOD

*TROD 21

*THOD 22

*TNOD 23

*THOD 24

*TOOE 25

*TUOD 26

*TROD 27

-TVOD 28

*TROD 29

*THOD 3ก

*THOD 31

*THOD 32

-TROD 33

-TROC 34

*THOD 35

*TดOS 36

मTOOD 37

*TYOD 38

*TOOD 39

*TROD 40

*THOD 41

*TROD 42

*TROD 43

*THOD 44

*TROD 45

सTROD 46

*THOD 47

-TWOD 48

*TOOD 49

-TROD 50

*TROD 51

*THOD 52

*TROD 53

TTOD 54

-TROD 55

*TMOL 56

*THOD 57

*THOD 58

*THOD 59

*TYOD 60

*THOD 61

-TWOL 52

*THกD 63

*TWOD 64

*Tกट 55

*THon 66

*THOD 67

*

P

THOD

$T$ TROD

$T$ TTOD

$T$ TROD ORNL-4595 SEF, "ORGRAPH" MANTAL POR USB OP "PIXPLT" 
ARRATS:

$X(N X) \&$ (NT) DEFINP TAE GPID POINTS PROA DHICH

XY (NX, NY) DATA POINTS RILL HAVE A CONTORR PLOT GERERATED

C.NC) CONTAINS THE CONTOOR LINE VALUPS NATCE DILL AE PLOTTED

IN TRE CALL TO "RCONTR":

CALL RCONTR (NC, C,XY, HX,X,NXP,NX,NDLTX,Y,NYP,NY,NDLTY)

VALUES OF X(IX)。Y(IY),E XY(IX,IY) VHICA RILL BE USED ARE DETERMINED BY DO LOOPS

D? - - IXIXNX,NX, NDLTX $\varepsilon$

DO - - IY=NYP, NY, NDLTY

"PLID" IDENTIPIFS PLOT NITH DATE, HASP LOG NOMBEB, $\varepsilon$ THE TIAF AT DHTCH JOB RAS EXECUTED

"PT. TD" USES "GTJN" (AR ASSEABLY LANGOAGE ROUTINE)

חSTALLY SUPPITED AS A HEX DECK

TF NO IDENTIPICATION OF PLOTS IS DESIREL, REHOVE THE CALL To "PLITR"

COMMON/LGND/C $(20)$, DESCR (40), SYMBL (20), NC, HS YEBL

COGMON/XYTN/OO,T2,TAU1,TAU2, XO, YO,ALPHA, DO, R, E, SIGMA, THETA, $1 \quad Q R, P N$

COAMON/XYT $2 C / P H(10), X M(10)$, IM (10), O4R,KOO,POOA2,B2

REAL R, KOO

DTAENSTON X(500), Y (50), XY (500,50), BUPPPR (3000). TITLEP (20)

INTEG ER PY (50), FN,PLOT, DY10, NPLOT/0/,PB,QR

DATA BIG/ZTFPPPFPF/, SPACE/

NSY ARI $=-1$

$N C=5$

C.ALL OQNEUS (O)

100 READ (5,80NO, END=165) TITLEP,PR, PLOT, QK, T, Q0,T2,TAU1, TAO2,

$1 \quad X 0, Y 0, A L P 4 A, 00, K, B, S I G M A, T H B T A, X E A X$

BOOC ONRAT (20A4/3I5/6P10.0/(7P10.0))

TITLPP $(19)=$ SPACE

TITI.PP $(20)=$ SPAC E

IP (XMAX.EQ. . . O) X BAX=BIG

$\mathrm{DY}=\mathrm{B}$

$Y I=0.0$

$\mathrm{DY}=\mathrm{B} / \mathrm{10} .0$

$D Y 10=1$

$\mathrm{R}=\mathrm{B}$

C DLOT=0, NO CONTOIR PLOTTING

IE (PLOT. EQ.0) GÓ TO 105

$D X=D X / 4.0$

$D Y=D Y / 4.0$

DY $10=4$

$105 \times \mathrm{T}=\mathrm{DX}$

no $110 \quad I=1,500$

$x(T)=X . T$

$x I=X I+D X$

110 CONTTNIS

ก) $11.5 T Y=1.50$

$\nabla(I Y)=P T$

$P Y(I Y)=Y I$

IE (YI.GE.B) GO TO 120

$Y I=Y I+D Y$

115 CONTINUTE

120 PRINT BกO5, TITLEP, FN, PLOT, QR,T,QO,T2,TAO1,TAD2,XO, YO, ALPBA, OO, $1 \quad K, B, X H A X$

8005 PORMAT $1 \%, 10 \mathrm{X}$. THO DIMENSIONAL TRANSIENT FAR-PIELD ANALSIS*/ $10 \times, 20 A 4 / 10 X$. PNNCTION NIFBER (FN)--0=GAUSSIAN LINE .

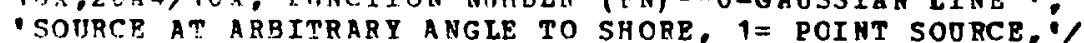
14X.', AND >1=MULTIPLE POINT SOURCE: FURCTIOA HOHBBR= .I2/ $10 X$. CONTOUR PLOT IF PLOT=1: PLOT=1. I1/

1OX, 'USF DERTVATIVR, OP Q PUNCTION IP QK=1: QK= , I1/

$1 \cap X, T=1, P 7,1, Q 0=, P 8,1, T 2=1, P 7.1$,

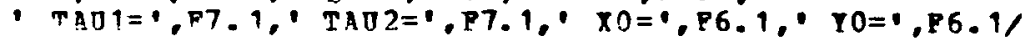

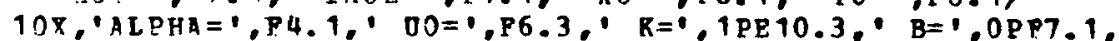
- $X$ MAX $=1,1 P P 12.6)$ IF (FN.EQ.0) PRINT BO10, SIGAA,THETA

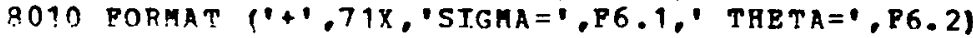

C INITIALTZP ARRAYS POR T.TNE SOURCE IP PH=0

C OR HULTIPLE FOINT SOORCE IP PN>1

TROD 79

TROD 75

TROD 76

TROD 77

TROD 78

TIOD 79

TROD 80

THOD 81

THOD 82

TROD 83

TROD 84

TWOD 85

THOD 86

TROD 87

TROD 88

TWOD 89

THOD 90

TWOD 91

THCE 92

TWOE 93

TYOD 94

THOD 95

TROD 96

THOD 97

TMOD 98

TWOD 99

TROD 100

TROD 101

TWOD 102

TROD 103

TMOD 104

TROD 105

THOD 106

THOD 107

TROD 108

TWOD 109

TrOD 110

TROD 111

THOD 112

TWOD 113

TROD 114

TWOU 115

THOD 116

TROD 117

TVOD 118

TWOD 119

TNOD 120

THOD 121

TROD 122.

TROD 123

TROD 124

TROD 125

TROD 126

TROD 127

THOD 128

TROD 129

TROD 130

TROD 131

THOD 1.32

TROD 133

TTOD 134

TROD 135

TUOD 136

TROD 137

TROD 138

THOD 139

THOD 140

TROD 141

TYOD 142

TOOD 143

TROD 144

TMOD 145 
IP (PN.GT. 1) RRAD BO15, (XM(I), YU(I), PM(I) , I=1,PN)

TROD 146

P.015 PORHAT (3F10.0)

IP (FN. TE. 1) CALL XYP1

IP (FN. F.Q. O) CALL XYP 2

PRINT $8020,(I, P \Psi(I), Y M(I), P M(I), I=1, P N)$

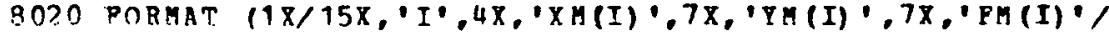

$1 \quad(14 X, I 2,1 P 3 P, 12.4)\}$

DRI NT 8025 , (PY (I) $I=1$, I P DY 10 )

R025 PORMAT (1Y/9X,'Y', I5, 10T9/8X,100(',')/5X,'X 1',100X,'1') $X M Y$ PN $=0.0$

DO $12.5 \quad \mathrm{~T}=1, \mathrm{PN}$

$X M X P N=A M A Y 1$ (XM (I), XHXFN)

125 CONTINII:

TT $2 n 0=(T-T ?) / \Pi 0$

YYMAX $=0.0$

Dก $140 \quad I X=1,500$

$X I=X(I X)$

$X Y 0=0.0$

DO $130 \mathrm{~T}=1, \mathrm{IY}$

$X Y(T X, I)=n .0$

130 COVTINIT

IF (XI.GT.XMAX.AND.XI.GT.XMXPN) GO TO 145

Jก $13.5 \quad I Y I=?, T Y$

$\nabla I=Y(I Y T)$

$X Y(I X, I Y I)=X Y T 2(X I, Y I, T)$

$X Y O=X Y O+X Y(I X, I Y I)$

IP (XT.GE.B) XYMAX=ABAX 1 (XY (IX,IYI), XYMAX)

135 CONTINTE

$I X I=X T$

IP (MOD (IXI,PB) - EQ,O) PRINT $9030, I X I,(X Y(I X, J), J=1, I Y, D Y 10)$

8030 FORMAT $(1 \times, T 5,1,11 \mathrm{P9}, 4,1 \%$

IF (XI.I.P.XMXPN.OR.XI.LR.TT2UD) GO TO 140

IP (YYO.EO. 0.0) GO TO 145

140 CONTINIT

145 PRINT Aก35

8035 PORAAT $\left(7 \times, 1^{\prime}, 100\left(^{\prime}, 1^{\prime}, 1^{\prime}\right)\right.$

QRITE (40) IX,IY,XY

IP (PLOT.EO.O) GO TO 100

NPLOT $=1$

C SET T.FNGTA OP PLOT

CALL QOQCDA $(5,24.0)$

$C(N C)=A J N T(X Y M A Y)$

$\mathrm{NC} 1=\mathrm{NC}-1$

$i=\mathrm{NC} 1$

Do $150 \quad I=1, N C 1$

$C(J)=r(. T+1) / 2.0$

$\mathrm{J}=\mathrm{J}-1$

150 CONTINUR

PRINT 3040, (C(I), I-1,NC)

9040 PORMAT ('0 CONTONR LEVP.T.S:', 10P10.4)

$X M I N=X(1)$

FIIIIN $=B I C$

DO $155 T=1, P N$

XMIN $=\operatorname{AMIN} 1$ ( XMM (I), XMIN)

PMIIN = AMIN T (PH (I), FMAIN)

155 CONTINTF.

FMMIN $=$ FMATN $* 50.0$

CALL FIXPLT (XMTN, X (IX), Y (1), T(IY) .'LINEAR', 'MECR', - 1.0,-1.0, 1 PUIPFER, 300ก, 'LONG $\$ \%$

CALL RCONTR (NC, C,XY,500,X, I,IX, I, Y, 1,IY, 1)

CALL LEFT (TTTLF P)

CALL TITLF $(0.4$, TITLEP, X\$', 751$)$

DO $160 \quad I=1,0 \mathrm{~N}$

$R(1)=X M(I)$

$X(2)=X M(I)$

$Y(1)=Y M(I)$

$Y(2)=Y M(I)$

CALL QQQCPA $(9$, AMIN 1 (PM (I) /PMHIN , 0.1))

CALL LINPLT $(X, 7,2,11,-1)$

160 CONTINUE

CALL QQOCPA $(9.0 .1)$

$T 800147$

TWO: 148

$T$ TEC 149

TR OD 1.50

TrOD 151

TWOD 152

TFOD 153

THOD 154

THOD 155

THOD 156

TROD 157

TROD 158

TROD 159

TROD 160

TROD 161

TROD 162

TNOD 163

TWOD 164

THOD 165

T9OD 166

TMOD 167

THOE 168

TROD 169

TWOD 170

THOD 171

THOD 172

THOD 173

TดOD 174

THOD 175

THOD 176

THOD 177

TROD 178

TWOD 179

TrOD 180

TROD 181

TROD 182

THOD 183

THOD 184

THOD 185

TROD 186

TYOD 187

THOD 188

TROD 189

THOD 190

THOD 191

TROD 192

TROD 193

TWOD 194

TEOD 195

TROD 196

TROD 197

TROD 198

THOD 199

THOD 200

TROD 201

TROD 202

TROD 203

TWOE 204

THOD 205

THOD 206

TROD 207

TROD 208

THOD 209

TROD 210

THOD 211

THOD 212

TROE 213

TROD 214

TDOD 215

THOE 216 
CALL PLID

GO TO 100

TROD 217

THOD 218

TROD 219

165 IF (NPLOT.EQ.1) CALL ADVANS

TROD 220

STOP 9999

END

TROD 221 
SURBOIITINT XYTT

COMMON/YYTN/OO, T2, TAD1, OAD2, XO, YO, ALPHA, DO, K, B, SIGMA, THETA,

XYTI $0 K$, EN

INTEGPR PN, OK

CORMON/RYT2C/PM (10), XM(10), YK (10), O4A,KUO,PUOA2,B2

PEAL $K, R \Pi$ RI

STTRY XPPT

C TNITIATIZF TERAS POR POINT SOURCE

C. OR MTLTIPLE POINT SOURCE

TF (F. GT. 1) GO TO 100

$X Y(1)=X 0$

$Y M(1)=Y 0$

$F M(1)=1.0$

$100 \pi 4 A=(10 /(4 . \cap * A L P H A)$

$k ! 10=k / U 0$

C PIOA2 =?*SORT (PI*Uก*ALPHA)

$P I \cap A 2=S Q R T(12.53664 * \because 30 A L P H A)$

$B 2=2.0 * B$

RTT TRN

ENTRY XYF 2

C. INTTIMLTZE VALUES POR FUNCTION XYT. (GAUSSTAN SOURCE AT ARBITRARY ANGLE)

C. CONVERT THETA TO RADTANS

THETA=THETA * $1.745329 \mathrm{E}-$ ?

C CALCUIATE THE F-PUNCTIONS

SINT $=\operatorname{STN}$ (THFTA)

$\operatorname{COST}=\operatorname{COS}(\mathrm{TH} F \mathrm{~T}$ A)

C CALCOIATE, THE XI PONCTIONS

$S ?=2.0 * S T G M$

$P S T=S 2 * S T N^{m}$

$X T 1=-52$

IF (VO.LE.PST) XI $1=-Y 0 / S I N T$

RYD $=R-Z \cap$

$x+2=52$

T.P (BYO.LE.FST) XI Z =BYO/SINT

C CALCULATE THE XM E YM VALUES FROM THE XI FUNCTIONS

DELTA $=(X I 2-X I 1) / 5.0$

DENOM = ERP (XI2/STGMA) -ERP (XI 1/STGMA)

DEL $2=D E T T$ T $/ 2.0$

$X M R=1.0$

DO $105 M=1,5$

$F M(M)=(E R P((X I 1+X M R * D E L T A) / S I G M A)-F R P((X I 1+(X M R-1.0) * D E L T A) /$ $S$ IGMA) $/$ DEN OM

TWOM $1=(2.0 * X M R-4.0) * D E L ?$.

$P M(M)=Y O+(X I 1+T$ HOF 1$) * S I N T$

$X M(M)=X O-(X I 1+T$ HOH 1$) * \operatorname{COST}$

$X M R=X M R+1.0$

105 CONTINTI

$\mathrm{PN}=5$

GO TO 100

END 


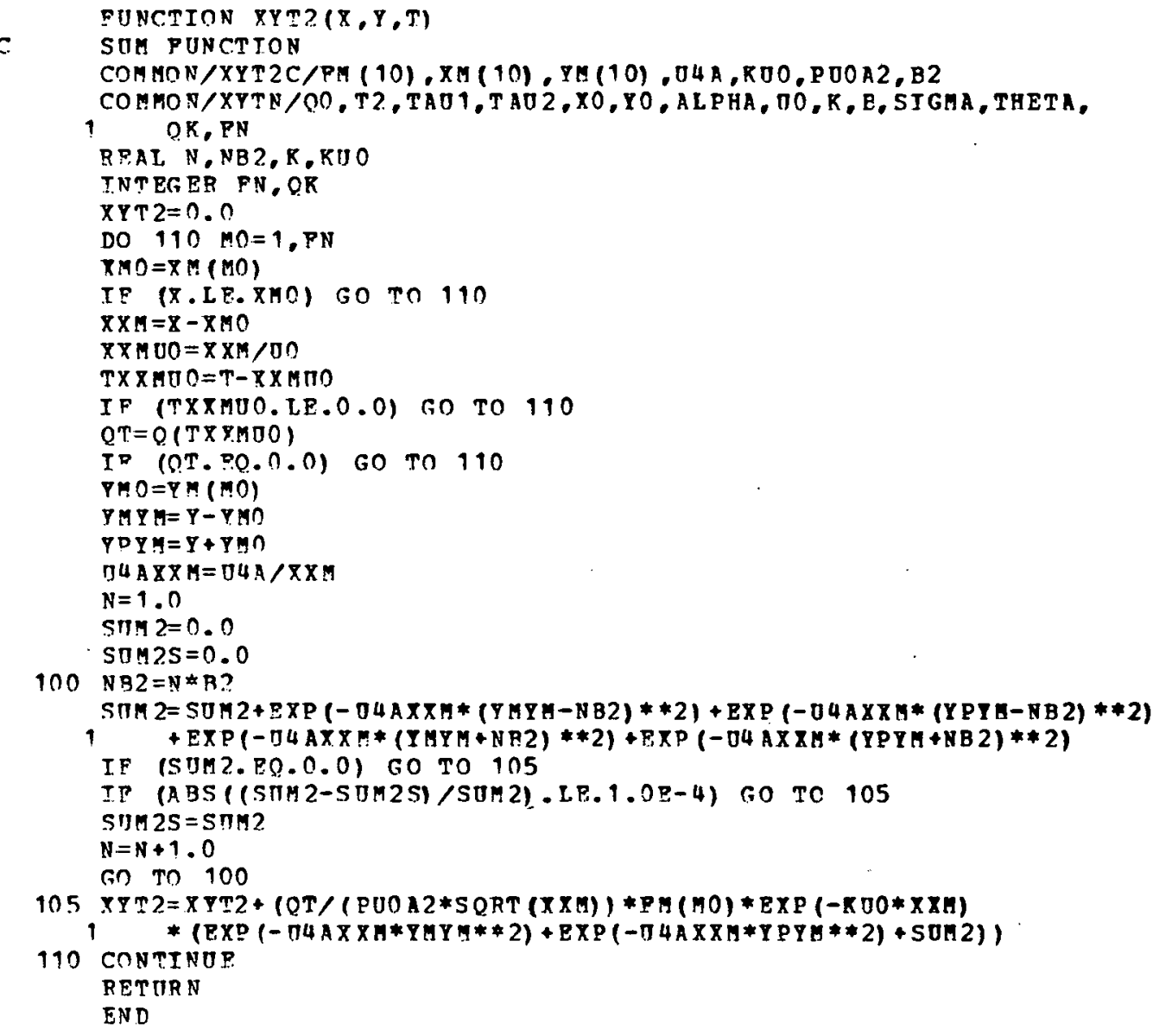

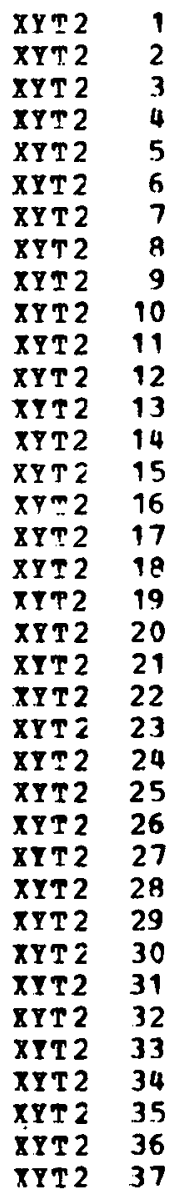




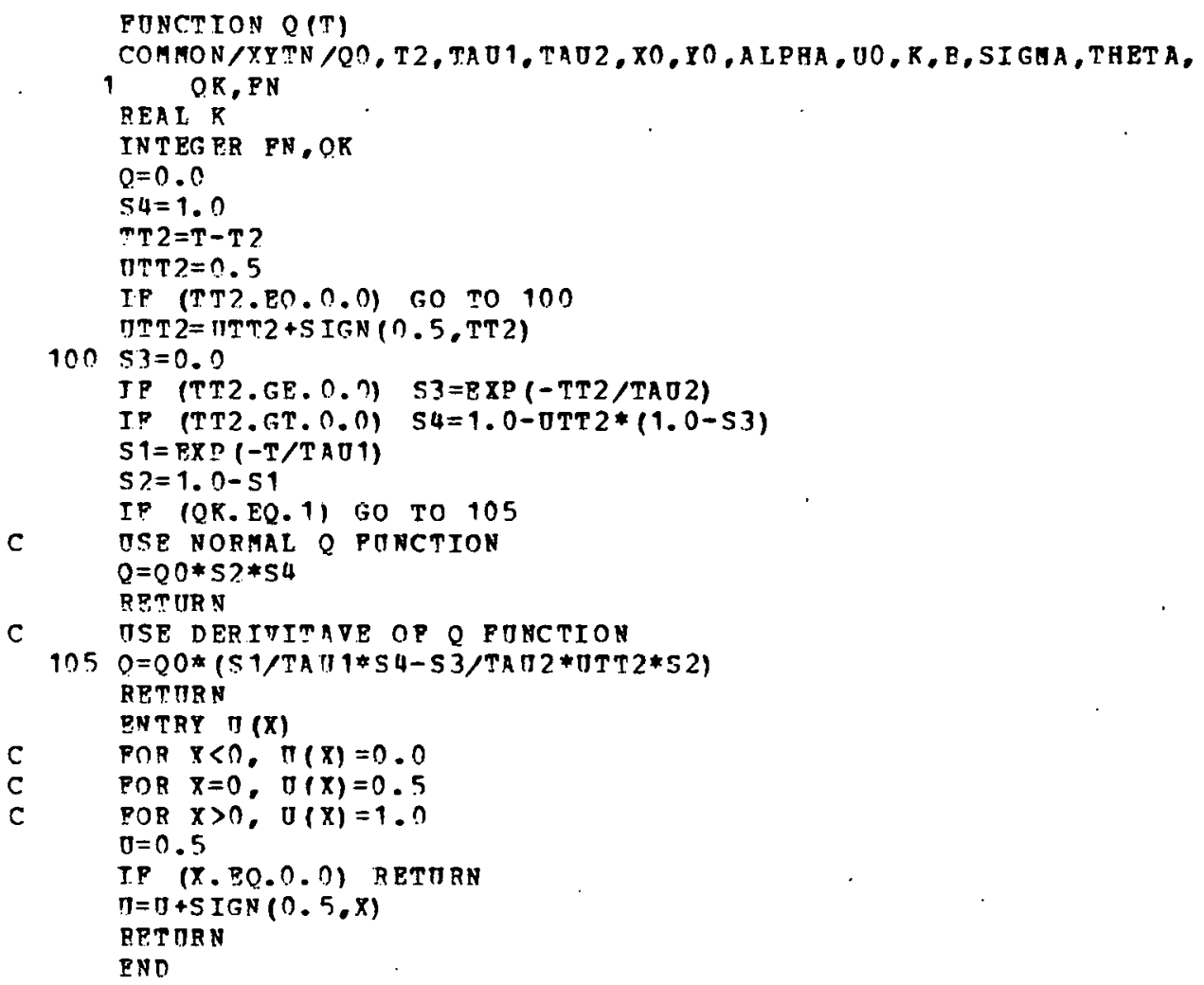




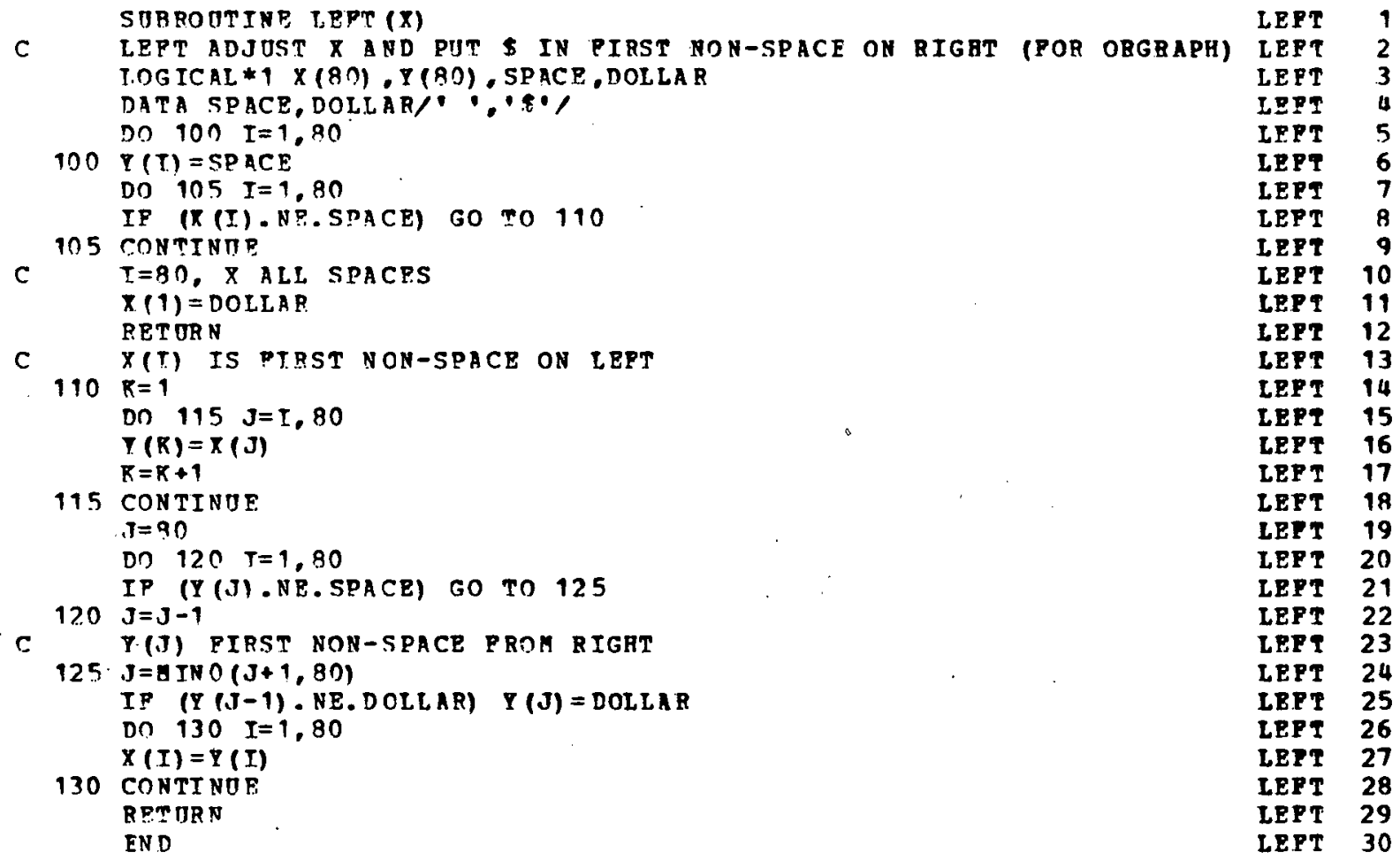




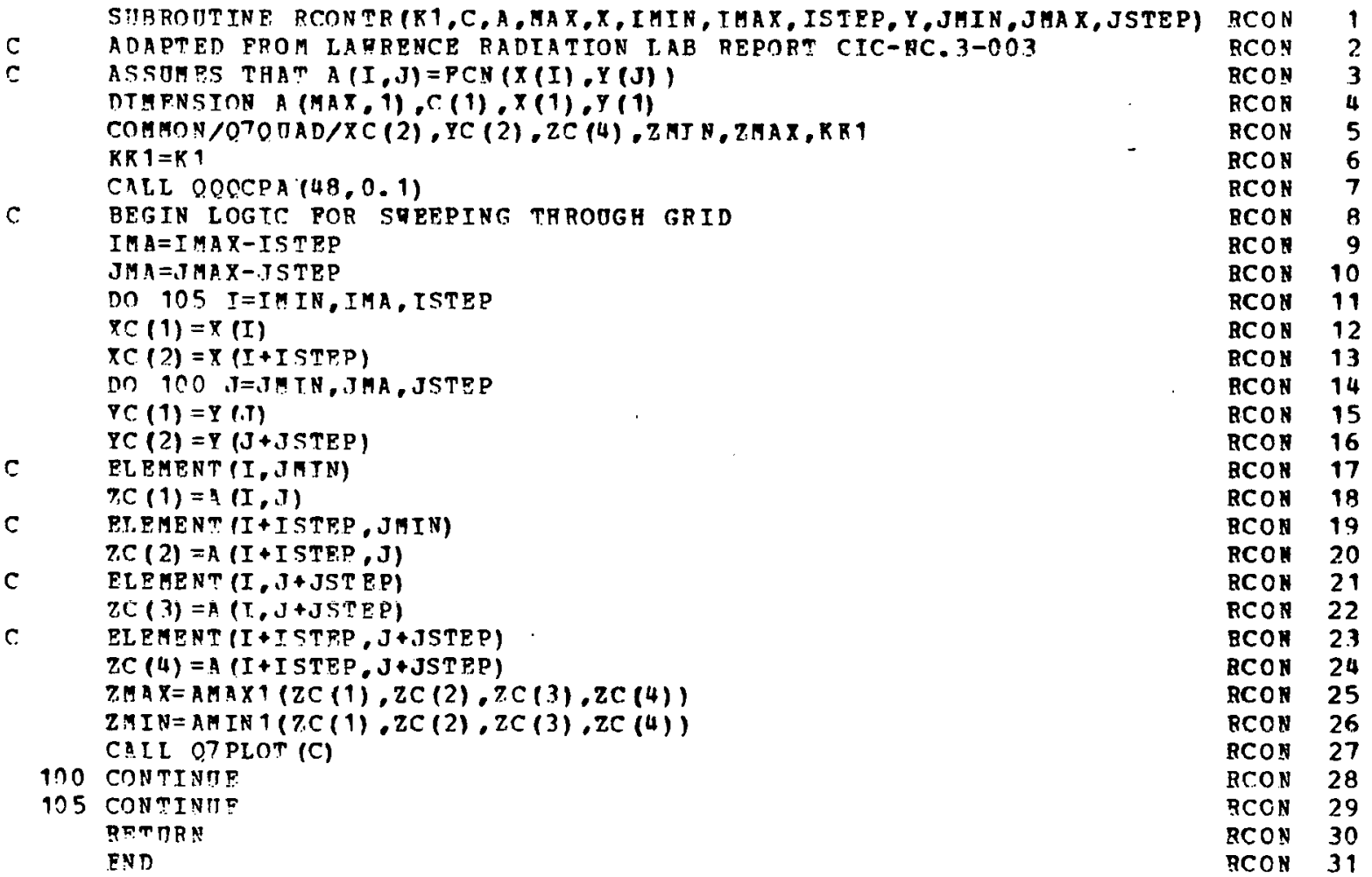




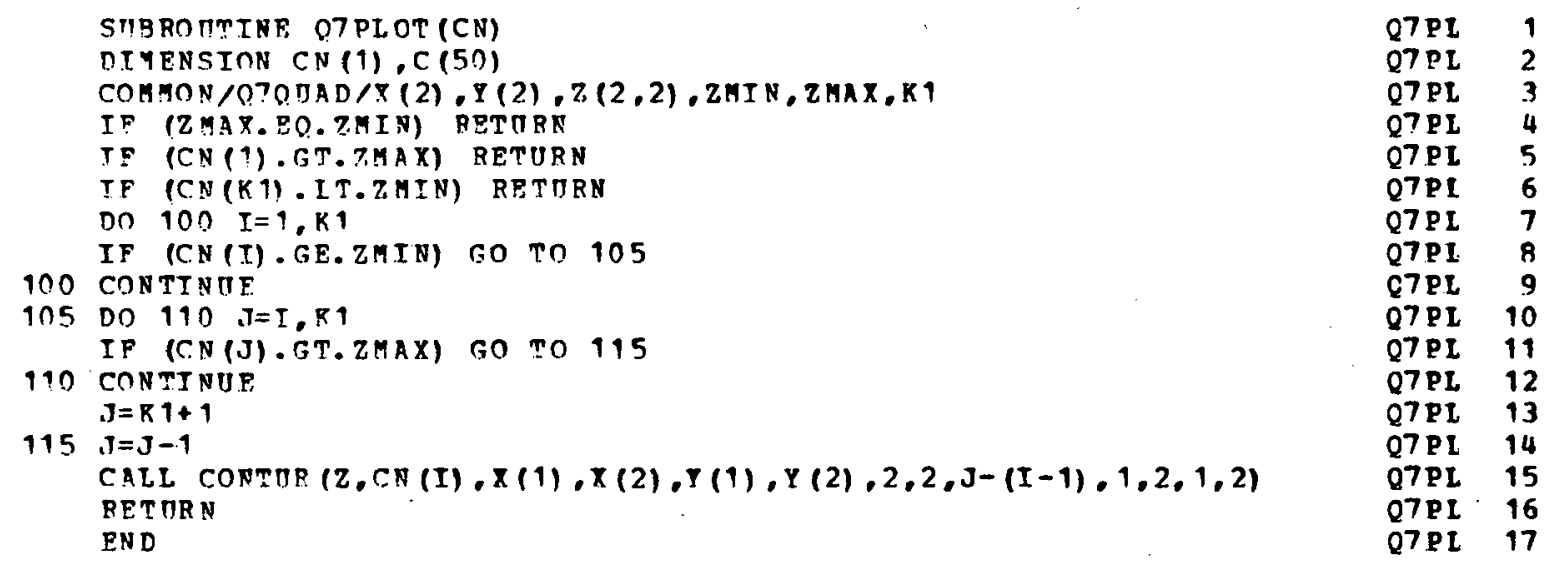


STBROTTTE CONMTR(Z, C, P1MIN, P1MAX, P2 MIN, P2MAX, A, R, NCL, AMIN,

150 A I I $N=2(I, J+1)$ GO TO 155

165 IF (C (K).LT.AMIN) BO T.SA $\nabla P_{t}=\mathrm{T}$ ISAVE $=\mathrm{J}$ RSA $\nabla E=K$ GO TR 190

$170 K=K+1$ IP (K.IF.NCL) GO TO 1 nn GO TO 185

175 CALL I,TRIS (Z,C, XINC, YTNC, KM, KN, KNCL) $11=1$ Go To 135

180 CALL UTRIS (, , , XTRC, YINC, RH, RN, RNCL) $J I=1$ GO TO 170

195 CONTTNUE

190 CONTINUE RFT IIR N EN $n$

CONT

CONT 4

CONT 5

$\operatorname{CONT} 6$

$\operatorname{CONT} 7$

Cont 8

$\operatorname{CON}$ ? 9

CONT 10

CONT 11

CONT 12

CONT 13

CONT 14

CONT 15

CONT 16

CONT 17

Cont 18

CONT 19

CONT 20

CONT 21

$\operatorname{CONT} 22$

CONT 23

CONT 24

CONT 25

CONT 26

CONT 27

Cont 28

CONT 29

CONT 30

CONT 31

CONT 32

$\operatorname{CONT} 33$

CONT 34

CONT 35

CONT 36

CONT 37

CONT 38

CONT 39

CONT 40

CONT 41

CORT 42

CONT 43

CONT 44

CONT 45

CONT 46

CONT 47

CONT 48

r.กNT 49

CONT 50

CONT 51

CONT 52

CONT 53

CONT 54

CONT 55

CONT 56

CONT 57

COHT 58

CONT 59

cont 60

COHT 61

CกNT 62

CONT 63

$\operatorname{CONT} 64$

CONT 65

conp 66 
SOBROUTINE LTRIS (Z,C, XINC, YINC, RM, KN, KNCI)

COMMON/CONT/II, ISAVB, JSA VE, RSAVE, X $(2,50), Y(2,50), \mathrm{CL}$

LTRI

DIMFNSION Z, (RM, KN) , C (RNCL)

$K=K S A \nabla E$

$I=I S A V E$

$J=J$ J $P$ \&

IP $(C(K), J, R, Z(T, J+1))$,

IF (C (K).LR.Z(I,J)) GO TO 105

GO Th 115

100 IP (C (K).I.T.Z.(I,J)) GO TO 115

ZSA VE= Z, $(I, J+1)-Z(I, J)$

T.F (ZSAVE. EO. 0.0$)$ ZSA VE $=1.0$

$Y(I I, K)=(C(K)-Z(I, J)) / 7, S A V E+\operatorname{PLOAT}(J)$

$X(I T, K)=T$

GO To 110

105 IP (C(R).LT.Z(T,J+1)) GO To 115

$Z S \& \nabla P_{i}=Z(I, J)-Z(I, J+1)$

IP (ZSAYE.EQ.0.0) ZSAVE= 1.0

$Y(I I, R)=(Z(I, J)-C(K)) / 7, S A V P,+\operatorname{PLOAT}(J)$

$P(I I, K)=I$

$110 \quad I I=I I+1$

115 IF (C $(R)$.LR.Z(I,J)) GO TO 120

IP (C (R). [R. z $(I+1, J))$ GO TO 125

Go ro 135

120 IF $(C(K), L T .7(I+1, J))$ Go To 135

7.SA $\vee P=7,(I, T)-Z(T+1, J)$

IF (ZSAVE.EQ.0.0) ZSAVE=1.0

$\nabla(I T, K)=\mathrm{J}$

$X(I T, K)=(Z(I ., J)-C(R)) / Z S$ AVE + PLOAT (I)

Go To 1.30

125 I.F (C (K).LT.Z(T,J) GO TO 135

$Z S A \nabla F=Z(I+1, J)-Z(I, J)$

IF (ZSAVR.EQ.0.0) ZSAVE $=1.0$

$Y(I I, K)=J$

$X(I I, K)=(C(K)-Z(I, J)) / Z$ SAVE +PLOAT (I)

$130 I I=I I+1$

IP (II.EQ.3) GO TO $\mathbf{1 5 5}$

135 IF (C (K) $-[. R . Z(T+1, J))$ so To 140

IP $(C(K) \cdot L P, Z(I, J+1))$ GO TO 145 RPTIIRN

140 IF (C (K) . LT.7.(I,J+1)) RETORN

$7, S A \cup E=Z(I+1, \pi)-Z(T, J \cdot 1)$

TF (ZSAVE.EO.0.0) 2SAVE=1.0

$D X=(C(K)-Z(I, J+1)) / Z S A V E+P L O A T(I)$

$D Y=(Z(I+1, J)-C(R)) / Z S A V E+\operatorname{PLOAT}(J)$

$I T=I I+1$

IP (II. FO. 3) GO TO 150

RET DR N

145 IF $(C(R) . I . T . Z(I+1, J))$ RETURR

$Z S A V E=7 .(I, J+1)-Z(I+1, J)$

IF (ZSAVE, PQQ.ก.D) R.SA YR= $=1.0$

$D X=(Z(I, J+1)-C(K)) / 7, S A V F+P I, O A T(I)$

$D Y=(C .(K)-7(I+1, J)) / 7, S A V E+P L O A T(J)$

$I I=I I+1$

IF (II.NE. 3) RETURN

$150 \times(2, K)=D X$

$Y(2, K)=D Y$

155 CALL SUBPLT(C(R))

$C L=C(R)$

RETIRN

EN D

TTR

LTRI

LTRI

LTRI

LT R I

LTRI

LTR I

LTRI

LTAI

LTRI 12

LTRI 13

ITRI 14

LTRI 15

LTRI 16

LTRI 17

LTR I 18

LTRI 19

LTRI 20

LTRI 21

LTRI 22

LTRI 23

LTRI 24

LTBI 25

ITRT 26

LTRI 27

LTRT 28

LTRI 29

LTRI 30

LTBI 31

LTRI 32

LTRI 33

LTRI 34

LTRI 35

LTRI 36

IT RI 37

LTRI 38

IT RI 39

LTRI 40

LTRI 41

LTKI 42

ITR I 43

LTRI 44

LTRI 45

LTRI 46

LTEI 47

LTRI 48

LTRI 49

LTRI 50

LTEI 51

LTRI 52

LTR I 53

LTRI 54

ITRI 55

LTRI 56

LTRI 57

LIRI 58

LTRI 59

LTRI 60

LTRI 61 
STBROUTINE IITRTS (Z, C, XINC, Y INC,KM, RN,KNCI)

COMMON/CONT/II, I SAVB, JSAVE, KSAVE, X $(2,50), Y(2,50), \mathrm{CL}$

DTHENSINV Z (KH,KN),C (RNCL)

$I=I$. SA VE

$. T=J S A$ VE

$R=R . S A \nabla E$

IP (C (K).LE.Z $(I, J+1))$ GO TO 100

T.P $(C(K) . L . T .(I+1, J+1))$ GO TO 105

Gn TO 110

100 TR $(C(K) \cdot L T \cdot Z(I+1, J+1))$ Go To 110

ZS A VE $=2,(I, J+1)-Z(I+1, J+1)$

J.F (ZSAVE.EO.0.0) ZSAVE=1.0

$X(I I, R)=(Z(I, J+1)-C(K)) / 7 . S A \nabla E+F L O A T(I)$

$Y(I I, K)=J+1$

$T I=I I+1$

GO TO 110

105 I? (C (K) . LT.2(I,J+1)) GO TO 110

ZSA VE= Z $(I+1, J+1)-Z(I, J+1)$

TF (JSAVP. E0.0.0) ZSAVE=1.0

$P(I I, K)=.7+1$

$X(I I, K)=(C(K)-Z(I, J+1)) / Z S A \nabla E+P L O A T$ (I)

$I T=I T+1$

110 IP $(C(R) \cdot T, E . Z(I+1, J+1))$ Go To 115

TP $(C(K) . L E .2(I+1, J)) 60$ TO 120

go To 125

$115 I D(C(K) \cdot L T \cdot 2(I+1, J))$ GO TO 125

ZSA VE $=Z(I+1, J+1)-Z(I+1, J)$

T.F (ZSAVE.EO.0.0) ZSAVE $=1.0$

$X(I I, K)=T+1$

$P(I I, K)=P L O A T(J+1)-(2(I+1, J+1)-C(K)) / Z$ SAVE

$I I=I I+1$

TP (II.FO. 3) GO TO 130

GO TO 125

120 IF $(C(K), I T, Z(I+1, I+1))$, so To 125

$\mathrm{ZSA} \vee \mathrm{E}=\mathrm{Z}(I+1, \mathrm{~J})-\mathrm{Z}(\mathrm{I}+1, \mathrm{~J}+1)$

IP (ZSAVE.EQ.0. O) ZSAVE $=9.0$

$X(I I, K)=I+1$

$Y(I I, K)=(Z(I+1, J)-C(R)) / Z S A \nabla E+P L O A T(J)$

$I I=T I+1$

IP (II.BO.3) GO TO 130

125 IF (IT.NE.?) RETURN

IP (CI..NP.C (K)) RPTDRN

CALL SOBPLT $(C(R))$

RETURN

130 CALL STEPLT $(C(K))$

RETTR N

END 


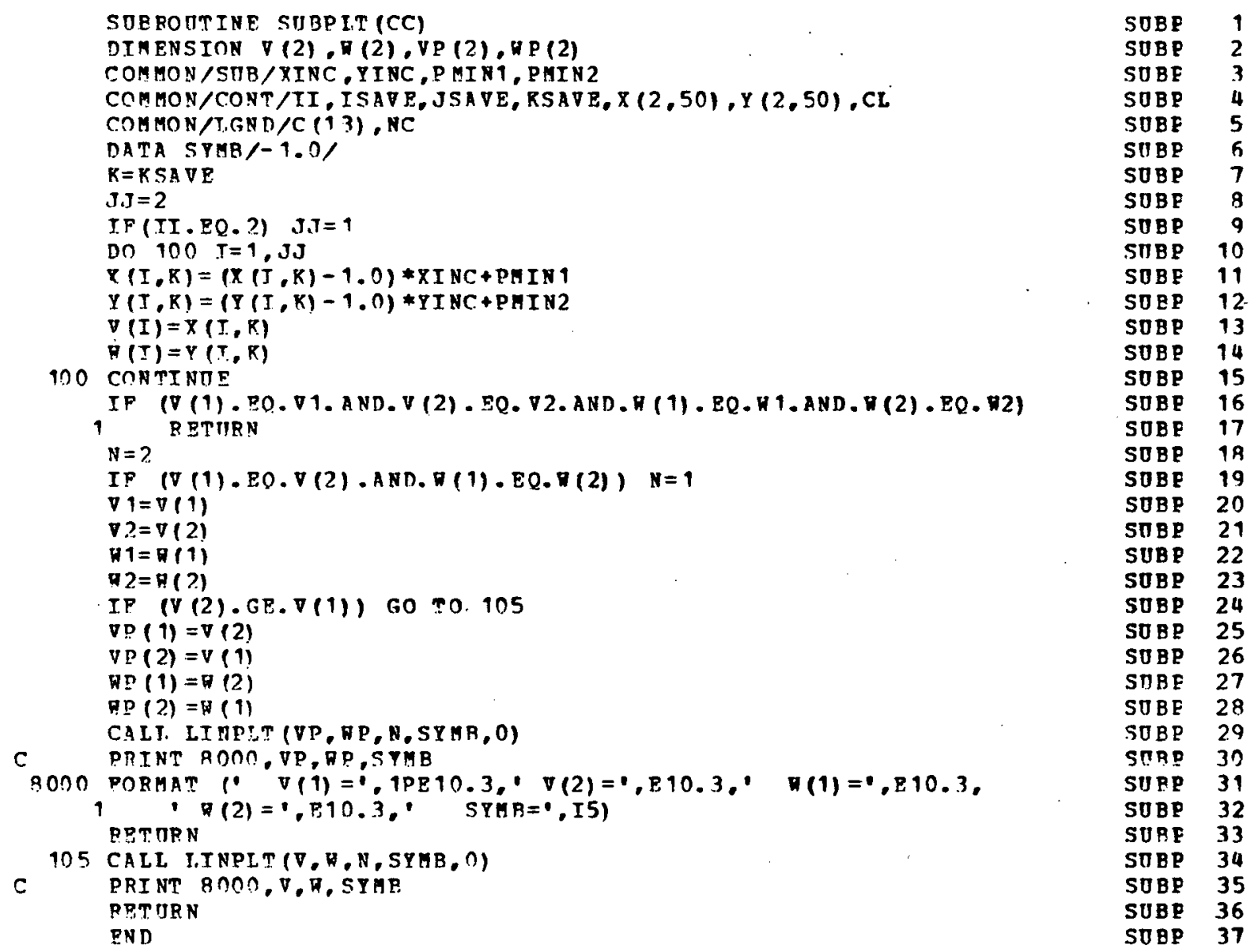


SUBROUTJNE PLTD

PLID 1

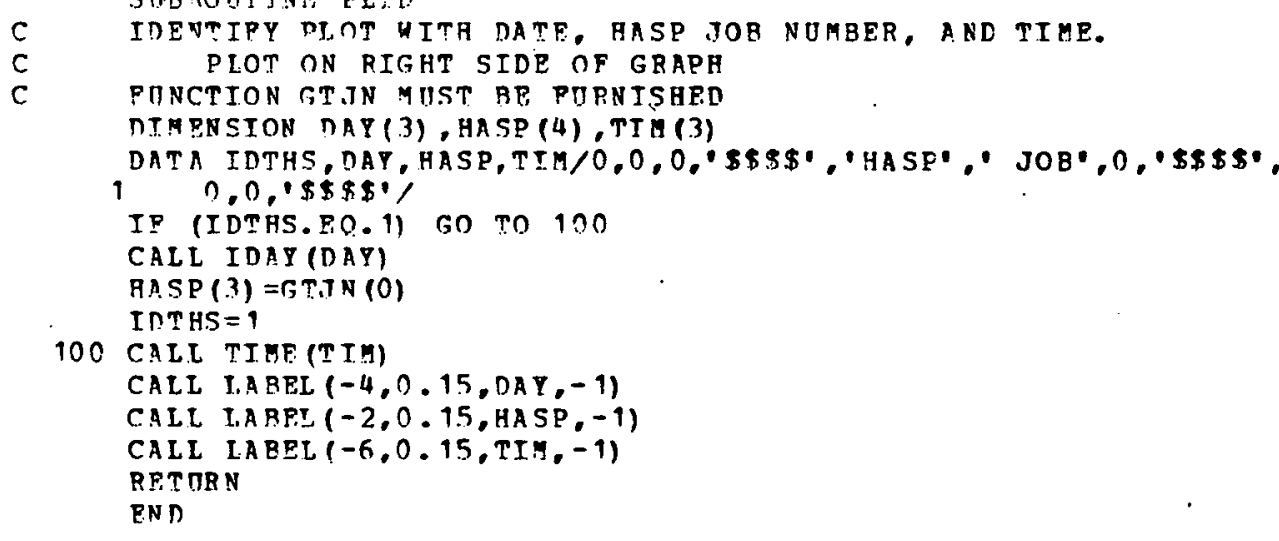

RET TRN

PL ID 2

PLID 3

PLID 4

PLID 5

PLID 6

PLID 7

PIID

PLID 9

PLID 10

PLIC 11

PIID 12

PLIT 13

PLID 14

PIID 15

PLID 16

PI.ID 17 
THIS PAGE

WAS INTENTIONALLY

LEFT BLANK 
ORNL/TM-5578

INTERNAL DISTRIBUTION

1. H. G. Arnold

2. S. E. Beall

3. C. R. Boston

4. R. W. Brocksen

5. R. S. Carlsmith

6. H. P. Carter

7. C. C. Coutant

8. J. S. Crowell

9. R. M. Davis

10. S. G. DeCicco

11. W. Fulkerson

12. H. W. Hoffman

13. J. T. Holdeman

14. M. E. LaVerne

15. D. W. Lee

16-25. E. C. Long

26. J. D. Mason

21-31. H. A. McLain
32. B. D. Murphy

33. A. A. Patrinos

34. M. R. Patterson

35. H. Postma

36. R. G. S. Rao

37. R. C. Robertson

38. M. W. Rosenthal

39-43. T. H. Row

44. P. R. Vanstrum

45-54. A. J. Witten

55. H. T. Yeh

56. H. E. Zittel

57. ORNL Patent Office

58-59. Central Research Library

60. Document Reference Section

61-62. Laboratory Records Department

63. Laboratory Records, ORNL R.C.

64-66. Technical Publications Department

EXTERNAL DISTRIBUTION

67. Director, Research and Technical Support Division, DOE, ORO 68-94. Technical Information Center, P. O. Box 62, Oak Ridge, TN 37830 